Review Article

\title{
Nutrient Sensor mTOR and OGT: Orchestrators of Organelle Homeostasis in Pancreatic $\beta$-Cells
}

\author{
Nicholas Esch, ${ }^{1}$ Seokwon Jo, ${ }^{1}$ Mackenzie Moore $\mathbb{D}^{1},{ }^{1,2}$ and Emilyn U. Alejandro $\mathbb{D}^{1}$ \\ ${ }^{I}$ Department of Integrative Biology \& Physiology, University of Minnesota Medical School, University of Minnesota, Minneapolis, \\ Minnesota, USA \\ ${ }^{2}$ Department of Surgery, University of Minnesota Medical School, University of Minnesota, Minneapolis, Minnesota, USA
}

Correspondence should be addressed to Emilyn U. Alejandro; ealejand@umn.edu

Received 11 September 2020; Revised 6 November 2020; Accepted 24 November 2020; Published 16 December 2020

Academic Editor: Yingke Xu

Copyright ( 92020 Nicholas Esch et al. This is an open access article distributed under the Creative Commons Attribution License, which permits unrestricted use, distribution, and reproduction in any medium, provided the original work is properly cited.

The purpose of this review is to integrate the role of nutrient-sensing pathways into $\beta$-cell organelle dysfunction prompted by nutrient excess during type 2 diabetes (T2D). T2D encompasses chronic hyperglycemia, hyperlipidemia, and inflammation, which each contribute to $\beta$-cell failure. These factors can disrupt the function of critical $\beta$-cell organelles, namely, the ER, mitochondria, lysosomes, and autophagosomes. Dysfunctional organelles cause defects in insulin synthesis and secretion and activate apoptotic pathways if homeostasis is not restored. In this review, we will focus on mTORC1 and OGT, two major anabolic nutrient sensors with important roles in $\beta$-cell physiology. Though acute stimulation of these sensors frequently improves $\beta$-cell function and promotes adaptation to cell stress, chronic and sustained activity disturbs organelle homeostasis. mTORC1 and OGT regulate organelle function by influencing the expression and activities of key proteins, enzymes, and transcription factors, as well as by modulating autophagy to influence clearance of defective organelles. In addition, mTORC1 and OGT activity influence islet inflammation during T2D, which can further disrupt organelle and $\beta$-cell function. Therapies for T2D that fine-tune the activity of these nutrient sensors have yet to be developed, but the important role of mTORC1 and OGT in organelle homeostasis makes them promising targets to improve $\beta$-cell function and survival.

\section{Introduction}

Analogous to the way in which dysfunctional organs can cause diseases and death, intracellular organelles that deviate from their normal physiological performance can disturb the functions and vitality of the cells in which they reside. As this review will discuss, the pandemic of diabetes in the United States and worldwide is a chief illustrator of this principle. Type 2 diabetes (T2D) is characterized by hyperglycemia [1], hyperlipidemia [2], and key changes in amino acid profiles [3] that are associated with alterations in peripheral insulin sensitivity and $\beta$-cell function. Important parameters of $\beta$-cell function include responsiveness to stimulation by nutrients (i.e., glucose and amino acids) and sufficient $\beta$-cell mass to regulate nutrient homeostasis in the bloodstream. Despite an initial phase of functional adaptation during the development of T2D, $\beta$-cells gradually lose their ability to regulate homeostasis due to sustained $\beta$-cell overwork caused by chronic and increasing insulin resistance [4]. Hyperglycemia and hyperlipidemia that accompany these changes are cytotoxic to $\beta$-cell health and function [5] because they disrupt organelle activities and activate pathways for programmed cell death. Organelle homeostasis is regulated by a vast number of mechanisms, many of which crosscommunicate with and regulate one another. In recent years, research has intently focused on uncovering these mechanisms in $\beta$-cells and learning how the functions of $\beta$-cell organelles are disrupted by sustained elevations in nutrient levels during prediabetes and T2D. Signals from intracellular nutrient sensors have emerged as particularly important regulators of $\beta$-cell function during the pathogenesis of T2D [6, 7]. However, the union between organelle dysfunction and nutrient-sensing pathways in $\beta$-cell failure has not been wholly recognized up to this point. In this review, we summarize how dysregulated signals from anabolic nutrient-sensing pathways during T2D integrate numerous modes of organelle 
dysfunction within $\beta$-cells, ultimately leading to their demise. In particular, we review how the activities of the endoplasmic reticulum (ER), mitochondria, lysosomes, and autophagosomes within $\beta$-cells are influenced by chronic and sustained stimulation of two key nutrient-sensor proteins, the mechanistic target of rapamycin (mTOR) and O-linked $\mathrm{N}$ acetylglucosamine transferase (OGT), and how these changes contribute to systemic $\beta$-cell failure. The catabolic nutrient sensor AMP-activated protein kinase (AMPK) is also important for $\beta$-cell function, and AMPK signaling is perturbed during T2D $[8,9]$. However, AMPK and organelle homeostasis in $\beta$-cells is understudied; this is a subject greatly in need of further research. We will address AMPK in this review when relevant, but our discussion of nutrient sensors will largely focus on mTOR and OGT. In addition to these nutrientsensing proteins, we discuss autophagy and inflammation, two mechanisms that regulate organelle homeostasis and are sensitive to nutrients status. Autophagy acts as an important intracellular process in $\beta$-cells that is used to maintain healthy pools of organelles, but when this process is disturbed, organelle homeostasis can become disrupted as well. By contrast, inflammation, which is chronically elevated in obesity and $\mathrm{T} 2 \mathrm{D}$, acts as an important extrinsic signal for promoting $\beta$ cell organelle dysfunction [10].

1.1. mTOR Signaling in $\beta$-Cells. mTOR is one of the primary nutrient-sensitive signaling switchboards that controls $\beta$-cell metabolism and function. This serine-threonine kinase exists in two distinct complexes within cells: mTOR complex 1 (mTORC1) and mTOR complex 2 (mTORC2). These complexes integrate and coordinate cell responses to signals from growth factors, mitogens, glucose, amino acids, oxygen, intracellular energy levels, and cell stress [11]. mTORC1 is primarily involved in the activation of anabolic pathways, energy utilization, cell growth, and proliferation, whereas mTORC2 largely functions as a regulator of cell survival and cytoskeletal reorganization [11]. Within the $\beta$-cell specifically, mTORC1 and mTORC2 play critical roles in the regulation of $\beta$-cell mass, insulin secretion, and maturation [12-20]. Short-term mTORC1 activation is beneficial for insulin biosynthesis and secretion [21] and can improve glucose homeostasis by expanding $\beta$-cell mass [22]. However, sustained mTORC1 activity in $\beta$-cells due to genetic manipulation or chronic nutrient excess results in $\beta$-cell dysfunction and eventual failure [23]. mTORC2 has been studied less extensively than mTORC1 but appears to have critical roles in $\beta$-cell adaptation to metabolic stress, $\beta$-cell proliferation, survival, and glucose-stimulated insulin secretion (GSIS) $[18,24]$. Crucially, $\beta$-cells from T2D individuals and mouse models display mTORC1 hyperactivity and mTORC2 hypoactivity [25]. This is in part mediated by chronic hyperglycemia [25] and may also result from elevations in key amino acids during T2D. mTORC1 activity is quite responsive to amino acids and is more sensitive to these nutrients than mTORC2 [26]. T2D, obesity, and insulin resistance have been associated with changes in serum amino acids, specifically elevations in branched-chain and aromatic amino acids [3]. Branched-chain amino acids, especially leucine, are potent activators of mTORC1 and may increase its activity during T2D [27]. In addition to increased nutrient stimulation, the changes in mTOR complex activity may be exacerbated and maintained by negative regulation of mTORC2 by mTORC1. mTORC1 hyperactivity and mTORC 2 hypoactivity in the context of T2D have many diverse and complex outcomes on a number of metabolic pathways, but in this review, we will focus on the junctions between mTOR signaling and organelle performance.

1.2. The Hexosamine Biosynthetic Pathway and Protein OGlcNAcylation. In addition to mTOR complexes, OGT is an additional intracellular nutrient sensor of critical importance in the $\beta$-cell [7]. OGT activity is driven by the hexosamine biosynthetic pathway (HBP), a metabolic pathway that integrates carbohydrate, amino acid, lipid, and nucleotide metabolism. It is estimated that approximately 3-5\% of intracellular glucose is shunted into the HBP and that this nutrient is the primary driver of flux, though amino acids and saturated fatty acids also direct the HBP. Metabolic studies have not been performed in $\beta$-cells to directly quantify the flux of HBP metabolites in response to glucose. However, it is apparent that glucose stimulates HBP in $\beta$-cells, as metabolites like glucosamine and $\mathrm{N}$-acetylglucosamine (GlcNAc) can recapitulate the effects of glucose on $\beta$-cell parameters like development [28] and gene expression [29]. In addition to glucose, glucosamine is also an important driver for flux, as this nutrient bypasses the first and rate-limiting enzyme of the HBP, glutamine:fructose-6-phosphate transaminase (GFAT). The ultimate product of the HBP is uridine-diphosphate-N-acetylglucosamine (UDP-GlcNAc). This substrate is used by OGT to glycosylate nuclear, cytoplasmic, and mitochondrial proteins at serine and threonine residues, a process referred to as O-GlcNAcylation. O-GlcNAcylation by OGT is distinct from the complex $\mathrm{N}$ - and $\mathrm{O}$-linked glycosylations occurring in the ER and Golgi during protein synthesis [30], and it is used to rapidly and dynamically modify protein activity, stability, and localization in a manner similar to phosphorylation. In fact, O-GlcNAcylation and phosphorylation frequently share protein targets, causing them to work in coordination or competition against each other and produce complex patterns of regulation [31]. Unlike phosphorylation, which is regulated by hundreds of kinases and phosphatases, the job of adding and removing O-GlcNAc is performed by only two enzymes: OGT and O-GlcNAcase (OGA), respectively. The activities of OGT and OGA enzymes are governed by UDP-GlcNAc availability, which depends on the intracellular concentrations of glucose, amino acids, and fatty acids and the activity of HBP enzymes. In addition, multiple forms of cell stress cause changes to global O-GlcNAcylation in an adaptive and cytoprotective manner [32].

$\beta$-cells demonstrate a marked use of HBP and protein $\mathrm{O}$ GlcNAcylation to fine-tune the coupling of nutrient availability to signaling pathways and organelle activity. OGT is highly expressed in pancreatic islets [33], and perturbations to $\beta$-cell O-GlcNAcylation through OGT deletion $[7,34]$ or OGA inhibition [35] cause $\beta$-cell failure and diabetes. OGA polymorphisms have been linked to T2D as well $[36,37]$. Moreover, prolonged hyperglycemia during diabetes causes sustained and excessive O-GlcNAcylation that compromises 
$\beta$-cell function [38]. Chronic hyperlipidemia appears to have more complicated effects on islet O-GlcNAcylation, but obesity in humans and high-fat diet (HFD) feeding in rodents appear to diminish the amount of OGT and OGlcNAcylation in islets [39]. As described in the subsequent sections of this review, dysregulated nutrient sensing through this pathway compromises the activities of several organelles crucial for $\beta$-cell function.

\section{Dysfunction of the Endoplasmic Reticulum}

The ER functions as a hub of activity for protein translation, modification, and folding, as well as regulation of calcium signaling and homeostasis, among other functions. In $\beta$-cells, the ER is largely dedicated to oxidative folding of proinsulin before it is trafficked to the Golgi [40]. When the demand for protein folding and modification exceeds the processing capacity of the ER, unfolded proteins accumulate within the ER lumen, and this disruption to ER homeostasis is referred to as "ER stress" [41]. ER stress is also prompted by perturbations to calcium levels within the ER, as many ER-resident proteins responsible for protein folding are calciumdependent. ER stress is attenuated through a series of negative feedback mechanisms termed "the unfolded protein response" (UPR). The UPR reduces ER stress through (1) transcriptional upregulation of proteins that enhance folding capacity, (2) impairment of translation to reduce protein load within the ER, (3) clearance of excess proteins through ERassociated degradation (ERAD), and, if ER stress is severe, (4) induction of autophagy to selectively target and degrade portions of damaged ER (i.e., ER-phagy) [41]. Additionally, the UPR regulates cell survival and will promote apoptosis when ER stress cannot be mitigated [41]. Though sustained or severe ER stress can be harmful, many secretory cells leverage the UPR induced by mild ER stress to optimize cell function [42]. The ER of $\beta$-cells in particular functions at the upper limits of its capacity to synthesize insulin, and the UPR induced by postprandial hyperglycemia allows $\beta$ cells to transiently surpass these limits to increase insulin production and meet the demands of the body during the absorptive state. Moreover, $\beta$-cells utilize mild ER stress to optimize proliferation [43].

The UPR is directed by three signal-transducing stress sensors located in the ER membrane: inositol-requiring enzyme-1 (IRE1), PKR-like ER kinase (PERK), and activating transcription factor 6 (ATF6) [41]. Activated IRE1 splices an mRNA that encodes a transcription factor for UPR target genes, X-box binding protein-1 (XBP-1) [44] [45]. When activated for sustained periods, IRE1 promotes apoptosis through activation of $\mathrm{c}$-Jun $\mathrm{N}$-terminal protein kinase (JNK) [46]. In $\beta$-cells, IRE1 also has roles in enhancing insulin biosynthesis in response to acute hyperglycemia [47] and degrading insulin mRNA during prolonged ER stress [48, 49]. PERK stalls global translation by phosphorylating the $\alpha$ subunit of eukaryotic translation initiation factor 2 (eIF2 $\alpha$ ), thereby preventing the assembly of ribosome initiation complexes and start codon recognition [50]. Simultaneously, phospho-eIF2 $\alpha$ promotes selective translation of UPRencoding mRNAs, including mRNA for activating transcrip- tion factor 4 (ATF4) [51]. ATF4 promotes the expression of the proapoptotic transcription factor C/EBP-homologous protein (CHOP), another critical regulator of cell death alongside JNK [52]. Activated ATF6 is cleaved in the Golgi and released into the cytoplasm where it can be trafficked into the nucleus to stimulate transcription of XBP-1, CHOP, and ER protein chaperones $[53,54]$. In the $\beta$-cell, ATF6 also represses insulin transcription [55] and may play a minor role in insulin secretion in response to glucose stimulation [56]. These proteins that facilitate the ER stress response are sensitive to nutrient levels and, as will be discussed in subsequent sections of this review, are finely regulated by nutrient-sensing proteins and pathways in $\beta$-cells.

During T2D, one avenue by which chronic hyperglycemia and hyperlipidemia mediate $\beta$-cell failure is excessive ER stress. Culturing primary human islets in high glucose for 48 hours induces the UPR [57], likely due to the increased insulin biosynthesis and chronic stimulation of secretion. Higher insulin production increases the load of nascent proinsulin within the ER, overwhelming the number of ER protein chaperones and inducing the UPR. Furthermore, the necessity for oxidative disulfide bond formation between proinsulin chains promotes the generation of reactive oxygen species (ROS) that can lead to oxidative damage within the ER [40]. Additionally, sustained insulin secretion depletes ER calcium stores [57], further worsening ER function and prolonging ER stress. Though glucotoxicity causes $\beta$-cell ER stress through multiple mechanisms, lipotoxic conditions are more potent initiators of ER stress [58] with saturated fatty acids being regarded as more potent activators than monounsaturates $[58,59]$. Free fatty acids deplete ER calcium and slow calcium uptake from the cytoplasm through the sarcoplasmic/endoplasmic reticulum $\mathrm{Ca}^{+}$-ATPase (SERCA), impairing the function of calcium-dependent ER proteins and leading to an accumulation of misfolded proteins within the ER [58]. Furthermore, high concentrations of palmitate (the major saturated fatty acid in the body) alter membrane fluidity and ER morphology, disrupting ER-toGolgi trafficking and causing proteins to stall within the ER and stimulate ER stress [60].

2.1. $\beta$-Cell ER Dysfunction in T2D. ER stress and a dysregulated UPR have important roles in the pathophysiology of diabetes. Several genetic contexts predispose individuals to ER stress-induced $\beta$-cell failure early in life $[61,62]$, and polymorphisms in ER stress sensors have been linked to T2D in certain populations [63-65]. Importantly, signs of $\beta$-cell ER stress are evident in ex vivo and in vitro studies with islets from T2D donors. Immunostaining of islets from T2D patients demonstrate elevations in downstream UPR targets [66], and electron microscopy (EM) imaging reveals significant expansion and morphological changes of the ER of T2D $\beta$-cells indicative of ER stress [67]. The nuclei of $\beta$-cells from individuals with $\mathrm{T} 2 \mathrm{D}$ and obesity show elevated amounts of the late-stage UPR transcription factor CHOP [68]. In vitro, glucotoxic conditions activate the UPR more readily in T2D islets than in islets from healthy donors [67]. Furthermore, transplantation of human islets to euglycemic mice induces mild ER stress and an adaptive UPR in 
these islets, but transplantation into diabetic mice induces proapoptotic ER stress signaling, suggesting that hyperglycemia may prolong ER stress past the point of beneficial adaptation [69].

Since in vivo studies of human islets present significant challenges, rodent models of diabetes have also been useful tools for elucidating the role of ER stress in $\beta$-cell dysfunction during chronic nutrient excess. Islets from diabetic leptinreceptor-deficient $d b / d b$ mice display signs of ER stress including elevated transcription of key UPR proteins, markers for their downstream targets, and ER morphological changes [66]. $\beta$-cells from Zucker diabetic fatty (ZDF) rats exhibit increased susceptibility to ER stress-induced by lipotoxic conditions [59]. By contrast, mice with a defective eIF2 $\alpha$ allele are unable to marshal a sufficient UPR when challenged with a metabolically stressful high-fat diet (HFD), leading to severe glucose intolerance due to poorly regulated ER stress that impairs insulin synthesis [70]. Importantly, the role of ER stress in $\beta$-cell failure is highlighted by findings that multiple mouse models of T2D can be improved by reductions in $\beta$-cell CHOP levels, thereby attenuating proapoptotic signals originating from ER stress $[7,71]$.

2.2. mTOR and Endoplasmic Reticulum Dysfunction. The interconnected relationship between mTOR signaling and ER stress has been established [72, 73]. mTORC1 activation can be both an upstream activator of ER stress and a downstream outcome. mTORC1 induces a mild UPR under physiologic conditions by enhancing protein synthesis and therefore increasing the protein load within the ER. Conversely, the ATF6 arm of the UPR activates upstream regulators of mTORC1 during pharmacologically induced ER stress [74]. Simultaneously, ER stress appears to suppress the activation of mTORC2 [75]; however, further studies are needed to evaluate whether there is a bidirectional relationship between ER stress and mTORC2 or if ER stress can stimulate mTORC2 in specific contexts. Importantly, activation of both mTOR signaling and the UPR promote cell survival during early signaling stages, but chronic ER stress and sustained mTORC1 activity positively reinforce one another in shifting the cell toward proapoptotic pathways.

Though there are limited studies on the specific mechanisms of mTOR-mediated ER stress in $\beta$-cells, they are generally consistent with findings from other tissues and cell types. Gene expression analysis of $d b / d b$ islets show associations between ER stress markers and increased ribosomal biogenesis that may be suggestive of increased mTORC1 activity directed by prolonged hyperglycemia [76]. Concurrent with this finding, constitutive mTORC1 activity in $\beta$ cells through genetic ablation of its upstream regulator TSC2 leads to ER stress in vivo that impairs $\beta$-cell function [22]. Mice in this model have improved glucose homeostasis in early life due to profound expansions in $\beta$-cell mass but become diabetic due to $\beta$-cell overwork and cell death. By contrast, inhibiting mTORC1 in human islets treated with lipotoxic and pharmacological ER stressors blunts the UPR and improves $\beta$-cell survival and GSIS [77]. Similarly, ER distension and proinsulin backlogging induced by lipotoxic conditions in INS-1E rat insulinoma cells can be ameliorated by stimulation of AMPK, which suppresses mTORC1 activity [78]. mTORC1 inhibition is also beneficial for $\beta$-cell function and glucose homeostasis in Akita mice, a model for ER stress-induced diabetes [79]. In addition to contributing to ER stress under genetic and lipotoxic circumstances, mTORC1 appears to synergize gluco- and lipotoxic conditions in $\beta$-cells. High glucose is known to exacerbate $\beta$-cell death caused by lipotoxic ER stress, and this is in part due to mTORC1-dependent upregulation of IRE1 and JNK. This asymmetric enhancement of the UPR specifically amplifies proapoptotic ER stress signals, compounding the effect of lipotoxicity [80]. Taken together, these studies highlight an important role for nutrient-driven mTORC1 overactivation in disruption of ER homeostasis that leads to $\beta$-cell dysfunction and apoptosis.

2.3. The Hexosamine Biosynthetic Pathway, O-GlcNAcylation, and ER Dysfunction. Similar to the case of mTOR, there is a complex interplay of cross-regulation between the UPR and HBP such that induction of one pathway commonly augments the other. HBP enzymes are upregulated by XBP1 in response to ER stress [81], while HBP flux generates metabolic intermediates that initiate ER stress [82]. In particular, high levels of glucosamine directly induce ER stress [83] and cause proteins to accumulate within the ER lumen by impairing N-linked glycosylations [84]. Downstream of the HBP, protein O-GlcNAcylation by OGT is elevated in response to pharmacological induction of ER stress [85] and is cytoprotective against ER stress and CHOP-mediated cell death in a number of cellular contexts [86-88]. Furthermore, suppression of translation by phospho-eIF $2 \alpha$ depends on OGT-mediated recruitment of proteins to cytoplasmic complexes that stall and degrade mRNA [89]. By contrast, modification of eIF $2 \alpha$ by OGT allosterically prevents its phosphorylation at Ser51, thereby impeding its downstream induction of $\mathrm{CHOP}$ and promoting cell survival [90]. The effect of hyper-O-GlcNAcylation on ER homeostasis in $\beta$ cells has not yet been investigated, though there are studies highlighting an important role for OGT in $\beta$-cell ER function. In murine $\beta$-cells, reducing O-GlcNAcylation through deletion of OGT contributes to ER stress-induced apoptosis that prompts diabetes, while concomitant ablation of CHOP in these mice delays the progression of hyperglycemia [7].

OGT also plays an important role in calcium homeostasis. Fatty acid-stimulated insulin secretion is also disrupted by OGT deletion due to reduced activity of the ER calcium pump SERCA2 [39]. The counterparts of SERCAs are ER calcium release channels, which promote calcium efflux from the ER in response to glucose and stimulation of secretion. The predominant release channel expressed in $\beta$-cells is $\mathrm{IP}_{3}$ receptor $3\left(\mathrm{IP}_{3} \mathrm{R}-3\right)$ [91]. $\mathrm{IP}_{3} \mathrm{R}-3$ channel activity is increased by O-GlcNAcylation [92], potentially allowing $\beta$-cells to fine-tune insulin secretion to nutrient status. Based on the regulation of eIF2 $\alpha$ and ER calcium transporters by OGT, inappropriate cellular O-GlcNAcylation during T2D may impair the UPR and initiate ER stress, thereby disrupting $\beta$-cell insulin synthesis, secretion, and cell survival. However, further studies are greatly needed to assess how OGT 
contributes to ER dysfunction in islets of T2D patients and mouse models.

2.4. Defects in Secretory Granules. The ER plays an essential role in insulin biosynthesis, but $\beta$-cell dysfunction can also stem from defects at the distal end of the secretory pathway in the secretory granules where proinsulin is processed to insulin. Therefore, we will briefly discuss secretory granule physiology and potential roles for mTOR and OGT in the regulation of these organelles. Parameters such as the number, size, shape, and core density of secretory granules are perturbed in $\beta$-cells of T2D individuals [93] and animal models [94-96] and are signs of dysregulation of insulin granule biogenesis and maturation. Granule maturation requires acidification of the granule lumen, high concentrations of zinc and calcium ions, and activity of proinsulin processing enzymes [97]. Disruption to these factors decreases the secretion of functional insulin. In addition, backlogging of proinsulin within the secretory pathway can stimulate ER stress; this is an additional mechanism by which palmitate induces ER stress [98]. Granule $\mathrm{pH}$ is regulated by vacuolar-(v)-ATPase proton pumps located in the secretory granule membrane [99]. Assembly of the v-ATPase complex is coupled to glycolysis [100], suggesting nutrient regulation of secretory granule acidification. Proteomic studies in neurons suggest putative O-GlcNAcylation sites on the vATPase complex [101, 102], and loss of OGT causes $\beta$-cells to display defects in proinsulin-to-insulin processing [103]. These findings may suggest malfunctional granule acidification when OGT is dysregulated, but these studies have not yet been performed in $\beta$-cells. In terms of secretory granule cation concentrations, Znt8 acts as the major transporter for zinc into $\beta$-cell secretory granules. Znt 8 genetic polymorphisms have been associated with variations in the risk of T2D [104]. This may be due to defects in $\beta$-cell function, as deletion of Znt8 from $\beta$-cells reduces the number of insulin granules, the amount of mature granules, and proinsulinto-insulin processing [105]. Intriguingly, EM imaging of Znt $8^{-1-} \beta$-cells resembles $\beta$-cells lacking mTOR, which have reduced mRNA expression of Znt8 and lower granularity despite normal proinsulin processing [106]. In terms of proinsulin processing, high levels of palmitate disrupt carboxypeptidase $\mathrm{E}(\mathrm{CPE})$, the enzyme that catalyzes the final step in proinsulin-to-insulin conversion within secretory granules [98]. Loss of CPE activity and proinsulin processing is also present in several mouse models of diabetes [107-109] including those due to loss of mTORC1 signaling [110] and deletion of OGT [103]. Altogether, these findings demonstrate significant disruptions to secretory granules during T2D, which can contribute to additional ER stress and impair $\beta$-cell function. There appear to be links between nutrientsensing proteins and secretory granule homeostasis, but additional studies in this area are warranted.

\section{Mitochondrial Dysfunction}

While the ER plays an important role in insulin biosynthesis, mitochondria are pivotal organelles in functional insulin secretion. In the classical pathway of insulin secretion that couples secretion to nutrient status, increased availability of substrates for mitochondrial respiration such as glucose and fatty acids increases production of ATP. Elevated cytosolic ATP concentrations then cause closure of $\mathrm{K}_{\mathrm{ATP}}$ channels in the plasma membrane. Subsequent depolarization of the membrane opens voltage-gated calcium channels and the influx of calcium promotes secretory granule fusion with the plasma membrane [111]. $\mathrm{K}_{\mathrm{ATP}}$-independent pathways involving cAMP, NADPH, long-chain acyl-CoA derivatives, amino acids, and superoxide have also been described, and these pathways also link mitochondrial metabolism to insulin exocytosis [112, 113]. Importantly, critical roles have been established for dysfunctional $\beta$-cell mitochondria in the pathology of T2D [114].

Mitochondrial dysfunction is largely characterized by excessive generation of reactive oxygen and nitrogen species (RONS). Chronic oxidative stress is a central mechanism in $\beta$-cell glucotoxicity, and reactions between cell components and mitochondrial RONS disrupt the metabolic pathways, organelles, and genes required for $\beta$-cell function [115]. In addition to cell damage, a high oxidative burden activates stress response pathways such as nuclear transcription factor-kappa B (NF- $\kappa \mathrm{B})$ and JNK that impair $\beta$-cell function and promote $\beta$-cell death if sustained $[116,117]$. $\beta$-cells are particularly susceptible to oxidative stress as they have been reported to express low levels of antioxidant enzymes [118] and less efficient DNA repair systems compared to other tissues [119].

Glucotoxicity can promote oxidative stress through a number of metabolic pathways in $\beta$-cells [115], but dysfunctional mitochondria are major drivers of oxidative damage and have been linked to impaired GSIS induced by highnutrient conditions $[120,121]$. Nutrient excess creates a surplus of electron carriers (e.g., NADH and succinate) within the mitochondria. When electron donation to the ETC from electron carriers exceeds the rate of oxidative phosphorylation, electron "leakage" from ETC complexes generates superoxide that can create other RONS and cause oxidative damage. As they are a major site of RONS generation during nutrient excess, mitochondria are poised to incur oxidative damage, a major cause of mitochondrial dysfunction. Intriguingly, inadequate nutrient conditions can also spur oxidative damage in vitro in rat islets [122] and INS1 cells [123], suggesting a complex relationship between nutrient status and RONS generation.

In addition to increased RONS production, changes in respiratory function, mitochondrial enzyme expression, mass and volume, morphology, biogenesis, turnover, calcium signaling, and membrane hyperpolarization are also crucial parameters of mitochondrial dysfunction [124]. Mitochondrial RONS cause oxidative damage to cell components outside the mitochondria and also create pernicious feedback loops of RONS production by damaging mtDNA, thereby further impairing proper mitochondrial function [125]. One way that mitochondria can respond to oxidative damage and compensate for mutated mtDNA is through mitochondrial fusion, but this comes at the cost of reduced mitochondrial efficiency that will impair cell function if sustained [125, 126]. By contrast, mitochondrial fission is employed to 
segregate damaged mtDNA and mitochondrial components, which can then be degraded by mitophagy (selective autophagy of mitochondria) [125]. In addition to fusion, changes in the expression of enzymes for repairing mtDNA (e.g., OGG1) [127] or uncoupling proteins (UCPs) that attenuate RONS production $[128,129]$ may also signify mitochondrial dysfunction. Finally, inadequate activity of mitochondrial transcription factor A (TFAM) can impair mitochondrial function, as TFAM regulates transcription and replication of mtDNA and is necessary for expression of respiratory complexes and mitochondrial biogenesis [130] as well as stimulus-secretion coupling and $\beta$-cell survival [131]. These markers are useful tools for assessing mitochondrial dysfunction and many are perturbed in $\beta$-cells by excessive nutrient exposure.

3.1. $\beta$-Cell Mitochondrial Dysfunction in T2D. Islets from T2D individuals and rodent models are rich with biomarkers for mitochondrial dysfunction that may underlie impairments in $\beta$-cell function [114]. Markers for oxidative stress are elevated in human T2D islets [132-134] and murine models $[135,136]$. Importantly, the onset of diabetes is preceded by elevations in islet superoxide content and markers for oxidative stress that correspond to mitochondrial defects [137] and the degree of GSIS impairment [133]. OGG1 is also upregulated in islet mitochondria of T2D patients, suggestive of a need for mtDNA repair due to high levels of oxidative damage [138]. T2D human [132] and mouse [129] islets also upregulate UCP2 to limit electron backlogging in the ETC and RONS formation. This upregulation reduces $\beta$-cell oxidative damage but also restricts mitochondrial ATP generation that impairs GSIS [132, 139]. T2D islets also show upregulation of complex I and ATP synthase, which may reflect an insufficient attempt by $\beta$-cells to offset the energetic costs of controlling RONS production through UCP2 [132].

T2D islets also have pronounced morphological changes indicative of mitochondrial dysfunction and oxidative damage. Mitochondria tend to be enlarged in islets from T2D individuals [132] and several T2D rodent models [140] which reduces oxygen consumption and may signify adaptation to oxidative damage under nutrient stress. At the same time, glucotoxicity induces mitochondrial network fragmentation in human islets [141] and rat models of T2D [142, 143]. Importantly, sustained mitochondrial fusion or fragmentation impairs GSIS, whereas appropriate mitochondrial size and networking are protective against glucolipotoxic cell death $[144,145]$. Chronic nutrient excess also reduces TFAM expression and activity in healthy human islets [113] though TFAM defects have not yet been reported in T2D $\beta$-cells. Altogether, nutrient-stressed $\beta$-cells demonstrate significant signs of mitochondrial dysfunction that impair functional insulin secretion.

3.2. $m$ TOR and Mitochondrial Dysfunction. Mitochondria are extensively regulated by mTOR signaling [146]. The expression of a substantial number of mitochondrial proteins, including TFAM, mitochondrial ribosomal proteins, and several respiratory chain subunits, depends on ribosomal translation involving eukaryotic translation initiation factor
$4 \mathrm{E}$ (eIF4E). eIF4E is inhibited by eIF4E-binding proteins (4E-BPs), and 4E-BPs are inactivated by mTORC1 [146]. As a result, mTORC1 signaling regulates mitochondrial energy production via regulation of mitochondrial protein translation [147]. Furthermore, mTOR complexes regulate fission, fusion, biogenesis, and mitophagy, thereby controlling mitochondrial mass and turnover as well [146, 147]. Additionally, specific combinations and/or high concentrations of particular amino acids regulate insulin secretion via mitochondrial-driven metabolism-secretion coupling [148]. Increased branched-chain amino acids during T2D and obesity that dysregulate mTORC1 activity may therefore represent another junction for mTORC1-dependent $\beta$-cell mitochondrial dysfunction $[3,27]$.

In terms of $\beta$-cell mitochondrial dynamics affected by mTOR signaling, dysregulated mTORC1 signaling may promote maladaptive changes in mitochondrial function. Though $\beta$-cell mitochondrial function and biogenesis are improved in the early life of the $\beta$-cell TSC2 knock-out mouse and contribute to improved insulin secretion [149], constitutive mTORC1 expression eventually causes increased mitochondrial oxidative stress and an accumulation of degenerate mitochondria [150]. This phenotype appears to be largely attributable to defective mitophagy in response to chronic mTORC1 activation. At the same time, the Krebs cycle, ATP production, and GSIS are impaired by rapamycin [151], a compound that inhibits mTOR and from which the kinase derives its name. Deletion of the mTOR kinase from $\beta$-cells results in defects in mitochondrial membrane potential, reduced mitochondrial activity, and increased oxidative stress, further underscoring the necessity of mTOR signaling in $\beta$-cell function [12]. Based on these reports that both hyperactivation and loss of mTORC1 signaling lead to mitochondrial dysfunction, mTORC1 activity must be finely regulated in $\beta$-cells to promote mitochondrial homeostasis. Hence, $\beta$-cell dysfunction arising from mitochondrial impairments is closely linked to the observation of dysregulated mTORC1 activity during T2D [25].

3.3. OGT and Mitochondrial Dysfunction. Mitochondrial function is also finely regulated by O-GlcNAc signaling. Specifically, a spliceform of OGT located within the mitochondria (mOGT) regulates mitochondrial respiration, morphology, and content [152]. A mitochondrial OGA isoform has not been identified, though OGA activity has been demonstrated within mitochondria [153]. Unfortunately, there have not yet been any studies examining the role of O-GlcNAcylation on mitochondrial dysfunction in $\beta$-cells, though loss of OGT in $\beta$-cells has been reported to cause abnormal mitochondrial morphology [7]. These morphological changes may be the result of altered O-GlcNAcylation of DRP1 and OPA1, two key proteins that regulate mitochondrial morphology $[154,155]$, but these mechanisms have yet to be elucidated. $\beta$-cells lacking OGT also display secretion deficits [7] that may be suggestive of inadequate mitochondrial respiration.

Fortunately, there is extensive research addressing mitochondrial O-GlcNAcylation during diabetes in cardiomyocytes which may provide insights into mitochondrial 
O-GlcNAcylation in $\beta$-cells. O-GlcNAc-omic profiling of rat cardiomyocyte mitochondria suggests that at least 88 mitochondrial proteins are O-GlcNAcylated, with respiratory complexes, TCA cycle enzymes, and fatty acid oxidation enzymes comprising the major targets of mOGT $[156,157]$. Chronic hyperglycemia produces marked changes in the OGlcNAc-omic profile of these proteins [157] which can in turn influence their expression and activity [158]. TFAM, a key transcription factor for mitochondrial proteins, is OGlcNAc modified under high glucose conditions and this modification reduces its mtDNA binding affinity [159]. OGlcNAcylation also regulates proteins that control mitochondrial fission and increases mitochondrial fragmentation in diabetic rat cardiomyocytes $[154,155]$. Increased $\mathrm{O}$ GlcNAcylation during diabetes also reduces the activity of OGG1, an important mtDNA repair enzyme, thereby leading to increased mtDNA damage [160]. Interestingly, it has been suggested that mOGT is localized along the inner mitochondrial membrane under physiological circumstances, but chronic hyperglycemia causes relocalization to the mitochondrial matrix. This altered localization of mOGT corresponds to reduced interactions with complex IV, which may underlie observations of reduced complex IV activity in diabetic mitochondria [153] and would be expected to increase mitochondrial RONS formation. In contrast to this finding, OGlcNAcylation of complexes I and IV is increased in rats bred to have poor mitochondrial respiration [161], though these factors could be secondary to other changes affecting mitochondrial performance.

Despite these findings, the relationship between changes in O-GlcNAcylation within the mitochondria and mitochondrial function are still not entirely clear. Short-term elevations in mitochondrial O-GlcNAcylation induced through acute pharmacological inhibition of OGA appear to improve mitochondrial function $[156,162]$, though these observations are not entirely consistent [163]. By contrast, increased O-GlcNAcylation due to chronic hyperglycemia or sustained in vivo OGA inhibition generally reduces mitochondrial efficiency $[153,162,164]$, though these findings have also been challenged [165]. At the same time, however, reducing mitochondrial O-GlcNAcylation through depletion of OGT or mOGT promotes mitochondrial dysfunction in multiple cellular contexts $[152,162]$. Rather than the total amount of mitochondrial O-GlcNAcylation, these studies suggest that long-term deviations from physiological levels of $\mathrm{O}$ GlcNAcylation negatively impact mitochondrial function. Mitochondrial dysfunction may also arise from changes in the rate of O-GlcNAc cycling (i.e., the addition and removal of O-GlcNAc). Tan et al. posit that O-GlcNAc cycling may be more pertinent for protein function than the mere presence or absence O-GlcNAcylation [158]. O-GlcNAc cycling is altered by manipulating the expression or activity of OGT and OGA because these enzymes have linked expression patterns that influence one another, and this may underlie the common observations in the aforementioned studies [158].

Upstream of OGT, the interactions between the HBP and oxidative stress have also been studied extensively [166]. Similar to the relationship between the HBP and ER stress, oxidative damage and the HBP also cross-regulate each other. In general, oxidative stress appears to promote OGlcNAcylation, but OGT regulation of oxidative damage appears to be more context-specific. For instance, though O-GlcNAcylation can promote the expression of antioxidant enzymes that quench RONS, HBP flux also promotes oxidative damage during glucotoxic conditions. In $\beta$-cells, GFAT overexpression induces oxidative stress that disturbs $\beta$-cell function [167]. However, pharmacological inhibition of OGA to increase $\beta$-cell O-GlcNAcylation does not reproduce this phenotype, suggesting a more important role for HBP flux and glucosamine-induced ER stress rather than changes in protein O-GlcNAcylation [167].

3.4. AMPK and Mitochondrial Dysfunction. Though studies of AMPK in $\beta$-cell organelle homeostasis are limited, there are several that highlight the role of AMPK in $\beta$-cell mitochondria. There are two isoforms of AMPK's catalytic $\alpha$ subunit, and islets from $d b / d b$ mice show repressed expression of the $\alpha 1$ isoform [19]. When both $\alpha 1$ and $\alpha 2$ are deleted from $\beta$-cells, mitochondria are smaller, fewer in number, and islets reduce transcription of genes for electron transport, oxidative phosphorylation, and mitochondrial biogenesis [19]. However, reducing expression of only the $\alpha 2$ isoform appears to have little effect on mitochondrial parameters beyond reducing mRNA expression of UCP2 [168], which may reflect compensation or greater importance of the $\alpha 1$ isoform in $\beta$-cells. Loss of LKB1, an activator of AMPK, produces severe mitochondrial dysfunction and disrupts GSIS [169]. In contrast to reducing AMPK activity, pharmacological stimulation of AMPK in INS-1E cells maintains mitochondrial morphology during lipotoxicity [78] but promotes RONS production and mitochondrial dysfunction in MIN6 cells (a mouse insulinoma cell line) under standard [170] or glucotoxic conditions [171]. Though these findings could also be attributable to differences in the cell lines, they may also suggest a complex role for AMPK and $\beta$-cell mitochondrial homeostasis that is context-specific.

\section{Lysosomal Dysfunction}

In addition to mitochondria, $\beta$-cell lysosomes are also critical organelles for regulating insulin secretion and allowing $\beta$ cells to function efficiently in response to nutrient flux. mTORC1 and AMPK are activated at the lysosomal membrane, making lysosomes hubs for intracellular nutrientsignaling [172]. The lysosomes also regulate the degradation of nascent secretory granules during nutrient deprivation, allowing $\beta$-cells to limit insulin secretion when it is not needed and providing carbon sources for $\beta$-cells to metabolize for survival [173]. Additionally, lysosomes are the terminal effectors of the autophagy pathway and function as important sites of macromolecule degradation that allow $\beta$ cells to adapt to early stages of glucolipotoxicity and remove defective organelles [174]. Despite the importance of this organelle, descriptions of lysosomal dysfunction are not well-established in the literature. In this section, we characterize lysosomal dysfunction as impairments caused by membrane damage, defective biogenesis, and insufficient degradative ability. 
Lysosomal damage is primarily characterized by lysosomal membrane permeabilization (LMP). The main driver of LMP is oxidative damage, but lipotoxic conditions that alter lysosomal membrane composition [175], proapoptotic signals, and inflammation can induce LMP as well [176]. Upon LMP, proteolytic hydrolases are released into the cytoplasm. Hydrolases from the cathepsin subclass activate caspases and other proapoptotic proteins to trigger cell death. Cathepsins directly promote mitochondrial outer membrane permeabilization and cytochrome $c$ release. Activated caspases trigger LMP in a positive feedback pathway. LMP can therefore act as both as an upstream initiator and a downstream accelerator for multiple forms of cell death $[176,177]$. Cathepsins also promote cell death through mitochondria- and caspase-independent pathways [178, 179]. Mild LMP can prompt lysophagy, i.e., the selective autophagic clearance of damaged lysosomes [180]. Signals from damaged lysosomes also promote inflammatory pathways and inhibit lysosomal biogenesis [181]. The latter outcome prevents cells from producing more lysosomes under stressful conditions that may lead to further LMP but compromises degrative capabilities if sustained.

Lysosomal biogenesis is primarily regulated by transcription factors EB (TFEB) and E3 (TFE3), which stimulate the expression of $\mathrm{v}$-ATPase subunits, acid hydrolases, and trafficking proteins important for lysosomal maturation [182, 183]. TFEB also regulates several genes for autophagy induction and degradation [184]. Nutrient levels [185], ER stress [186], and mitochondrial stress [185] regulate TFEB translocation, suggesting that lysosomal biogenesis is largely a response to metabolic stress that is used to enhance degrative pathways to restore cell homeostasis. However, sustained stress can lead to nuclear exclusion of TFEB, thus limiting lysosomal biogenesis and the ability of cells to manage excessive nutrient influx [185].

Lysosomal dysfunction can also arise when intralumenal enzyme activities are impaired. Deficiencies of key lysosomal enzymes (e.g., hexosaminidases, galactosidases, and cathepsins) cause undigested substrates to accumulate, which contributes to the pathology of lysosomal storage diseases and neurodegenerative disorders [187]. Additionally, inadequate cleavage of procathepsin zymogens disrupts lysosome function, causing lysosomes to swell and impair autophagic flux [188]. The pathogenesis of pancreatitis is in part driven by defective procathepsin processing that disrupts lysosomal activity in this manner [189]. Lysosomal alkalization can also promote lysosomal dysfunction as many lysosomal enzymes require an acidic $\mathrm{pH}$ to function. Finally, lysosomal incapacitation can result from the accretion of lipofuscin. Lipofuscin is a crude cross-linked mesh of oxidized macromolecules, metal cations, and sugar residues that accumulates within cells as they age because it cannot be degraded or eliminated $[190,191]$. Lipofuscin primarily accumulates within lysosomes, where it impairs hydrolase activity and obstructs autophagic flux [192] while also making lysosomes more vulnerable to LMP from internal oxidative damage [193] due to its propensity to accrue iron and promote ROS generation [194]. Lipofuscin is enriched in aged $\beta$-cells and may be associated with age-related decline in $\beta$-cell function [195].
4.1. $\beta$-Cell Lysosomal Dysfunction in T2D. Lysosomal function appears to be perturbed in $\beta$-cells in response to nutrient excess. Islets from T2D individuals $[196,197]$ and human islets treated with glucolipotoxic conditions [171] display an accumulation of autophagosomes within their cytosol. These observations may in part be due to lysosomal dysfunction during T2D and glucolipotoxicity, as dysfunctional lysosomes reduce autophagosome clearance, leading to increased prevalence of autophagosomes. In terms of lysosomal damage, LMP is induced in $\beta$-cells by glucolipotoxicity in vitro, likely through mechanisms involving ER stress [188] and enhanced mitochondrial RONS generation [198]. Additionally, inhibiting cathepsin D partially reverses glucolipotoxic cell death in murine islets, highlighting the importance of LMP in nutrient-induced $\beta$-cell failure [188]. However, it has also been reported that $\beta$-cells from T2D individuals have reduced transcription of cathepsin B and D [196] and downregulation of lysosome-associated membrane protein 2 (LAMP-2) [199, 200]; these findings may suggest low lysosomal number and reduced TFEB activity. In fact, TFEB translocation to nuclei is reduced in T2D islets [196, 199], and islets from HFD-fed mice show reduced transcriptional expression of TFEB [201]. Furthermore, TFEB and LAMP$2 \mathrm{~A}$ are decreased in cardiomyocytes of several mouse models of diabetes and obesity, demonstrating more broadly that chronic glucolipotoxicity reduces lysosomal biogenesis through TFEB dysregulation [202]. In vitro studies in INS-1 cells reveal that TFEB overexpression exerts a protective effect against glucolipotoxic cell death [201], demonstrating the significance of changes in TFEB expression and activity during T2D. Finally, in terms of disrupted degradation, glucotoxic conditions cause procathepsin accumulation within lysosomes that enhance $\beta$-cell apoptosis by impairing lysosomal activity and autophagic flux [203]. Similarly, treatment of INS-1 cells with palmitate disrupts lysosome function by reducing lysosomal acidity and cathepsin L activity [204]. Additionally, GSIS is impaired in the $\beta$-cells of diabetic Goto-Kakizaki rats due to reduced activity of "classical" lysosomal enzymes (e.g., cathepsin D and acid phosphatase) and hyperactivity of $\alpha$-glucosidases associated with malfunctional lysosomal systems [205]. Lysosomal accumulation of lipofuscin, however, does not appear to be more prevalent during obesity and T2D [195], though research in this area is quite limited.

4.2. mTOR and Lysosomal Dysfunction. Despite its intimate relationship with the lysosomes, how mTOR may regulate or respond to lysosomal stress has not been thoroughly studied. In myotubules with acid $\alpha$-glucosidase deficiency, enlarged and defective lysosomes demonstrate a reduced ability to release and inactivate mTOR during nutrient deprivation [206]. Similar lysosomal defects in $\beta$-cells may also hamper mTOR inactivation, though this remains to be studied. In contrast to enzymatic disruption, LMP causes swift and efficient delocalization of mTOR from the surface of the lysosome and initiates robust induction of autophagy at the site of lysosomal damage, thereby limiting the release of lysosomal contents into the cytosol [207]. When mTORC1 is active, however, it prevents lysosomal biogenesis by 
impairing TFEB translocation and stability [185]. This may support the observation that TFEB is less frequently observed in T2D $\beta$-cells exposed to chronic nutrient excess with hyperactive mTORC1 $[199,201]$. Reduced mTORC1 signaling has been reported to decrease lipofuscin accumulation in several tissues [208, 209], including in the context of T2D [210]; however, it has been reported that the prevalence of lipofuscin in $\beta$-cells is not increased by T2D or obesity [195]. $\beta$-cells may have mechanisms for adapting to and limiting lipofuscin accumulation in the context of elevated mTORC1 activity, but additional research will be needed to investigate this matter. AMPK also has important roles in lysosomal membrane integrity [207], biogenesis [211, 212], and hydrolytic ability [213]. However, these roles have yet to be explored in $\beta$-cells.

4.3. OGT and Lysosomal Dysfunction. Hyperglycemia has been used to drive lysosomal dysfunction in many of the studies described above, which would be expected to increase the amount of UDP-GlcNAc-substrate for OGT. However, the direct role of O-GlcNAcylation in lysosome dysfunction has been understudied. OGT recruitment to the cathepsin $\mathrm{D}$ promoter and hyper-O-GlcNAcylation of transcriptional corepressors silences gene transcription [214, 215], allowing fine regulation of lysosomal activity by nutrient levels at the transcriptional level. If this same pattern occurs in $\beta$-cells, the observation of reduced cathepsin $\mathrm{D}$ expression in T2D islets [196] may in part result from hyperglycemia-driven O-GlcNAcylation of the transcriptional regulators and machinery at the gene's promoter, though this has not yet been studied. The gene for $\beta$-galactosidase, another important lysosomal enzyme, may also be subject to O-GlcNAc regulation [216]. Beyond these studies, however, the role of OGT and lysosomal homeostasis is largely unknown.

\section{Autophagic Dysfunction and Regulation of Organelle Homeostasis}

Autophagy is a process characterized by the targeting and delivery of cellular contents and organelles to lysosomes to maintain cellular homeostasis. Autophagy is a critical modulator for $\beta$-cell organelle homeostasis [217], insulin secretion during fasting conditions [173], and secretory granule turnover [218]. In $\beta$-cells, autophagy is required to combat glucolipotoxicity, mitigate ER stress, and to maintain healthy pools of organelles in order to protect $\beta$-cell mass and function during nutrient excess. Genetic deletion of autophagyrelated 7 (Atg7), an important protein in this pathway, highlights the importance of functional autophagy as insufficient autophagy impairs $\beta$-cell proliferation, survival, and insulin secretion [219] and increases $\beta$-cell vulnerability to lipotoxicity $[220,221]$.

Several types of autophagy have been described to maintain cell function. Autophagy can be nonspecific or target specific cell components and organelles (e.g., mitophagy to selectively degrade mitochondria), and three major categories of autophagy have been described: macroautophagy, microautophagy, and chaperone-mediated autophagy. An additional form of autophagy relevant to $\beta$-cells is crino- phagy, which involves the direct fusion of secretory granules with lysosomes [222, 223]. Because secretory granule membranes and their associated proteins are recycled rather than degraded, this form of autophagy is an energy-efficient method leveraged by secretory cells to eliminate excess secretory granules [224]. For instance, crinophagy is markedly increased in $\beta$-cells by genetic deletion of Rab3a, which is an important protein in the secretory pathway [212]. Increasing crinophagy allows $\beta$-cells to prevent an overaccumulation of insulin granules when levels of insulin biosynthesis are still normal but secretion is impaired. Crinophagy is also responsive to glucose exposure, and the highest rates of induction in murine islets appear to occur at intermediate levels of glucose that promote insulin biosynthesis but do not trigger secretion [223]. Protein kinase D (PKD) is a major regulator of the fate of insulin granules. Loss of PKD signaling leads to constitutive secretory granule degradation, maintains mTORC1 activity, and suppresses macroautophagy [225]. Despite its importance, $\beta$-cell crinophagy in the context of T2D has not yet been studied, and it is unclear whether defects in this process may be augmented in T2D to contribute to $\beta$-cell dysfunction. However, there have been a large number of studies examining macroautophagy in the context of T2D, so we will focus our discussion of autophagy on this subtype. Hereafter, "autophagy" in this review refers specifically to the process of macroautophagy.

The mechanisms of macroautophagy have been thoroughly studied and described; briefly, this process involves the sequestration of cytoplasmic components in doublemembraned autophagosome vesicles that fuse with lysosomes to deliver their enclosed cargo [226]. Macroautophagy is initiated by the ULK1 complex, which is regulated by mTORC1 and induces Beclin-1 (Becn1) relocation to the ER membrane to nucleate the autophagosome. Further association with several components of the autophagy machinery such as Atg7 and microtubule-associated protein 1A/1B light chain-3 (LC3) is required for the expansion and completion of autophagosome formation. The specificity of autophagy depends on the recruitment of ubiquitylated targets by autophagy receptors such as p62/SQSTM1 that mediate interaction with LC3 proteins embedded in the autophagosome membrane [227]. Once targets are enclosed within the autophagosome, they are trafficked to the lysosomes. The outer membrane of the autophagosome fuses with the lysosomal membrane and subsequently the inner membrane, and enclosed contents are degraded by lysosomal hydrolases.

The two major forms of autophagic dysfunction are impaired autophagic flux and hyperactive induction of autophagy [228]. Impaired flux may arise from insufficient initiation of autophagosome formation or defects in autophagosome-lysosome fusion. The former can result from aberrant suppression of initiators of autophagy by upstream regulators (e.g., nutrient availability or cell stress), whereas the latter may result from changes in fusion proteins, lysosomal alkalization, or insufficient lysosome number. Accumulation of dysfunctional organelles, protein aggregates, or metabolites may signify inadequate autophagic flux. Accumulation of autophagosomes or autophagy proteins (commonly LC3-II, the lipidated form of LC3 associated with 
autophagosomes) can also indicate impaired autophagy; however, these observations should be combined with additional lines of evidence since they may just as easily indicate hyperactive induction of autophagy [229]. Too much autophagy can disrupt the function of organelles, and dysregulated autophagic signaling can initiate a unique form of programmed cell death [230]. Defects in TFEB activity also contribute to autophagic dysfunction, as TFEB regulates a number of autophagy genes in addition to those for lysosomal biogenesis [184].

5.1. Autophagic Dysfunction in $\beta$-Cells in T2D. A number of studies report perturbed autophagy in the $\beta$-cells during T2D and gluco/lipotoxicity. $\beta$-cells from T2D individuals have a higher density of autophagic vacuoles and autophagosomes per unit volume [196] and an accumulation of p62 $[231,232]$ that may suggest deficits in autophagic flux. Autophagosome and p62 accumulation are also observed in $\beta$-cells from several T2D mouse models [201, 220, 221, 232]. Furthermore, islets from T2D individuals contain a higher proportion of dead $\beta$-cells that display signs of autophagy-associated cell death [196]. Treatment of human and rat islets and INS-1E cells with palmitate induces autophagy that confers protection against ER stressinduced $\beta$-cell death and demonstrates the protective role of autophagy during acute nutrient stress [233-235]. Sustained lipotoxicity, however, appears to impair autophagic flux in islets and INS1 cells [197, 204]. In addition to the lysosomal defects that arise from lipotoxicity, this impairment may be attributable to a shift in autophagic targeting. For instance, in the islets of $o b / o b$ mice, total autophagic activity is increased but is skewed toward lipophagy (autophagic targeting of triglycerides and lipid droplets) to combat lipotoxicity, leading to reduced clearance of substrates associated with p62 (i.e., ubiquitylated proteins and organelles) [221]. However, in HFD-induced $\beta$-cell dysfunction, these impairments of autophagic flux can be attenuated by concurrent intermittent fasting that transiently alleviates nutrient excess [201]. In addition to impairments in autophagic flux, inappropriate activation of autophagy is also detrimental to $\beta$-cell health and function. Loss of the $\beta$-cell transcription factor pancreatic duodenal homeobox 1 (Pdx1) increases autophagy and cell death in MIN6 cells which can be delayed with the autophagy inhibitor 3-methyladenine (3-MA) [236]. Similarly, $\mathrm{Pdx} 1$ insufficiency in vivo causes a loss of $\beta$-cell mass; however, impairing autophagy through genetic reduction of Becn 1 in this same model can preserve $\beta$-cell mass [236]. In addition to affecting $\beta$-cell survival, mice with a constitutively-active Becn1 mutant display hyperactive autophagy during HFD feeding and this causes excess degradation of insulin granules and impaired GSIS [237]. While autophagy in human T2D $\beta$-cells needs to be investigated further, it is clear that sustained nutrient excess disrupts the $\beta$-cell autophagy system.

Autophagy is an important mechanism for regulating the clearance of defective or stressed organelles. The most studied form of organelle-specific autophagy in $\beta$-cells has been mitophagy. $\beta$-cells of diabetic Goto-Kakizaki rats show signs of increased mitophagy due to elevated mitochondrial stress
$[143,238]$. Additionally, deletion of Atg7 in $\beta$-cells disrupts clearance of defective mitochondria and causes an accumulation of swollen and deformed mitochondria [191, 219]. Several molecular targets in $\beta$-cells have been shown to regulate mitophagy. The mitochondrial Rho GTPase Mirol is critical for $\beta$-cell mitophagy, and deletion impairs mitochondrial and $\beta$-cell function [239]. Similarly, overexpression of the regulator of calcineurin 1 (RCAN1), which suppresses autophagy, impairs Mirol-mediated mitophagy in $\beta$-cells [240]. Furthermore, cytosolic accumulation of p53, via ER and oxidative stress, decreases mitophagy by inhibiting Parkin, an E3 ubiquitin ligase that labels defective mitochondria for degradation [241]. As previously discussed, mitochondrial dysfunction is evident in human islets from T2D donors, increasing the need for mitophagy. However, $\beta$-cells from islets of T2D humans, diabetic mice, and HFD-fed mice show reductions in Miro1, thereby leading to reduced mitophagy, mitochondrial dysfunction, and impaired insulin secretion [239]. Mitophagy markers in peripheral blood mononucleocytes are elevated in prediabetic individuals, likely as an adaptive mechanism to manage mitochondrial oxidative damage, but progressively decrease with the advancement of T2D. Importantly, these changes correlate with $\beta$-cell dysfunction, mitochondrial oxidative stress, and increased HbA1C, which may implicate glucotoxicity as a driver of aberrant $\beta$-cell mitophagy [200]. ER-phagy and lysophagy have not been studied in $\beta$-cells as much as mitophagy, but still remain important modes for restoring or disrupting homeostasis of their respective organelles. The fact that ER stress and the UPR are major stimuli for autophagy and that autophagy induction helps mitigate ER stress in $\beta$-cells $[79,242-244]$ indicates the important role of autophagy in ER homeostasis. Autophagy-deficient $\beta$-cells lacking Atg7 display ER distension [219] suggestive of luminal protein accumulation and potential ER dysfunction. Autophagy impairments in T2D $\beta$-cells may therefore disrupt ER turnover and impair the attenuation of ER stress, though this remains to be studied. To our knowledge, there is currently no evidence of $\beta$-cell lysophagy. However, disrupted lysophagy has been observed in diabetic mouse podocytes and contributes to their dysfunction during hyperglycemia [245]. Future studies of autophagic targeting of these organelles in $\beta$-cells are greatly needed.

\subsection{Regulation of $\beta$-Cell Autophagy by $m T O R$. In addition to} promoting anabolic pathways for cell growth and proliferation, an extensively studied role of mTORC1 is the suppression of autophagy [246]. In the genetic mouse model of constitutive $\beta$-cell mTORC1 activity through deletion of TSC2, $\beta$-cells are unable to initiate autophagy in response to ER stress or nutrient deprivation and have impaired autophagosome-lysosome fusion [150]. Similarly, ex vivo studies with human islets show sustained mTORC1 activation in response to glucolipotoxicity that suppresses $\beta$-cell autophagy, leading to dysregulated ER stress and insufficient mitophagy that cause cell death [197]. However, apoptosis caused by lipotoxicity and ER stress can be prevented through rapamycin-induced suppression of $\mathrm{mTORC} 1$ and stimulation of autophagy $[77,79]$. By contrast, ablation of a key mTORC1 
adaptor protein, Raptor, leads to dysregulated $\beta$-cell autophagy and cell death [110], suggesting important differences between pharmacological and genetic inhibition of $\mathrm{mTORC} 1$ in terms of their effect on the regulation of autophagy and $\beta$-cell survival that may involve timing, duration, and specificity of inhibition. Similarly, stimulation of AMPK in MIN6 cells also promotes autophagy-mediated cell death under standard conditions [247]. However, under lipotoxic conditions, AMPK stimulation is actually protective against $\beta$-cell death due to autophagy upregulation [247-249]. In general, sustained changes in mTORC1 activity cause dysregulation of autophagy, ultimately disrupting $\beta$-cell function and survival. While data on AMPK and autophagy is more limited, AMPK appears to be maladaptive when it unnecessarily increases autophagy but can be beneficial for $\beta$-cells when it is acting as a protective mechanism to nutrient stress.

5.3. Regulation of Autophagy by OGT. mTOR signaling is the major regulatory pathway that links the nutrient availability to autophagy, but OGT also acts to fine-tune and amplify autophagic signals [250]. Currently, there are no studies that directly link O-GlcNAcylation to autophagy in $\beta$-cells. However, regulation of autophagy by O-GlcNAcylation has been studied in other tissues. Increased O-GlcNAcylation of autophagic proteins (e.g., Becn1) is associated with suppression of autophagic flux in cardiomyocytes isolated from $d b / d b$ diabetic mice [251]. O-GlcNAcylation also regulates critical mediators of autophagosome-lysosome fusion in HeLa cell lines and limits their activity $[252,253]$. By contrast, O-GlcNAcylation of ULK1 has shown to be an activating posttranslational modification for autophagy initiation in mouse hepatocytes and several human cell lines $[254,255]$. Other studies in mouse cortical astrocytes and cancer models show varying degrees of correlation between O-GlcNAcylation and autophagy [256-258]. It is evident that the relationship between OGlcNAcylation and autophagy is tissue-and contextdependent. Given that $\beta$-cell O-GlcNAcylation is important for both basal function and adaptation to HFD [7], the relationship between O-GlcNAcylation and autophagy in islets requires further studies.

\section{Inflammation, Nutrient Sensing, and Organelle Dysfunction in $\boldsymbol{\beta}$-Cells}

In addition to sustained nutrient stress from hyperglycemia and hyperlipidemia, chronic low-grade inflammation has also been well-documented in individuals with T2D and obesity [10]. Longstanding inflammation is characterized by abnormal circulation of proinflammatory cytokines such as tumor necrosis factor $\alpha$ (TNF $\alpha)$, interleukin- $1 \beta$ (IL-1 $\beta$ ), and interleukin-6 (IL-6). These cytokines contribute to the development of T2D and related complications across multiple organ systems [10]. T2D humans and in animal models, increased levels of cytokines, chemokines, and immune cell infiltration have been observed in islets [259-261]. Chronic islet inflammation has been shown to exacerbate $\beta$-cell dysfunction and contribute to apoptosis [260-263]. This is in part because $\beta$-cells both secrete and respond to cytokines [264]. Importantly, chronic hyperglycemia activates inflam- matory pathways in $\beta$-cells [265] and increases cytokine production and subsequent recruitment of inflammatory cells to islets [266, 267]. Several mechanisms of $\beta$-cell failure discussed in this review including ER stress, oxidative stress, and glucotoxicity can both induce inflammation and result from inflammation induced by excess nutrients [268].

Bidirectionality extends to inflammation and mTOR as well. Inflammation can activate the mTOR pathway through ER stress or TNF- $\alpha$, which may contribute to dysfunctional insulin signaling $[269,270]$. mTOR activity can play both protective and detrimental roles in the development of T2D due to tissue-specific differences that may improve or impair cell function. Proinflammatory cytokines activate IKK which promotes activation of mTOR as well as NF- $\kappa$ B, a critical transcription factor that regulates the inflammatory process [271]. In immune cells, mTOR plays important roles in regulating cell metabolism, cytokine production, antigen presentation, macrophage differentiation, and tissue infiltration during the immune response [272]. In the setting of chronic inflammation, inhibition of mTOR with rapamycin reduces islet size and insulin content and increases $\beta$-cell apoptosis [273]. Beyond this finding, studies in this area are limited, and the interaction of inflammation with the mTOR pathway in $\beta$-cells is an area in need of future study.

Given the role of O-GlcNAcylation in the cellular response to physiological stresses [274], OGT is also poised to respond and regulate inflammation. In immune cells and in the inflammatory process, O-GlcNAcylation links environmental conditions to intracellular signaling events which can contribute to the development of disease states such as type 1 diabetes and other autoimmune disorders [275, 276]. Multiple studies have shown that there is a complex regulation of the immune system by O-GlcNAcylation that is dependent on the cellular context and nutrient availability $[276,277]$. Despite progress in the area, the role of OGlcNAcylation in islet inflammation remains incompletely understood and warrants further investigation.

6.1. Regulation of Inflammation by NF- $\kappa B$. The NF- $\kappa \mathrm{B}$ complex has regulatory roles in innate and adaptative immunity, inflammation, and apoptosis $[275,276]$. NF- $\kappa$ B activity has been linked to the pathogenesis of T2D, metabolic syndrome, and related complications $[263,278,279]$ by promoting the expression of a number of proinflammatory cytokines including TNF- $\alpha$, IL-1, and IL- 6 . NF- $\kappa$ B is responsive to high glucose environments, circulating cytokines, and oxidative stress arising from nutrient excess and organelle dysfunction [280]. Chronic NF- $\kappa$ B activity decreases expression of insulin, GLUT-2, and Pdx-1 in $\beta$-cells [281], and glucolipotoxicity induces NF- $\kappa \mathrm{B}$ signaling in $\beta$-cells that enhances $\beta$-cell death [282].

mTOR and OGT have been shown to affect multiple components of the NF- $\kappa \mathrm{B}$ pathway. mTOR regulates the activation of NF- $\kappa B$ [283] and links NF- $\kappa$ B to hyperglycemia in macrophages [284]. The NF- $\kappa$ B subunits RelA and c-Rel are subject to O-GlcNAcylation, which increases NF- $\kappa \mathrm{B}$ transcription activity in the setting of hyperglycemia and in response to TNF- $\alpha[277,285,286]$. OGT-mediated OGlcNAcylation also stimulates NF- $\kappa \mathrm{B}$ activity in pancreatic 


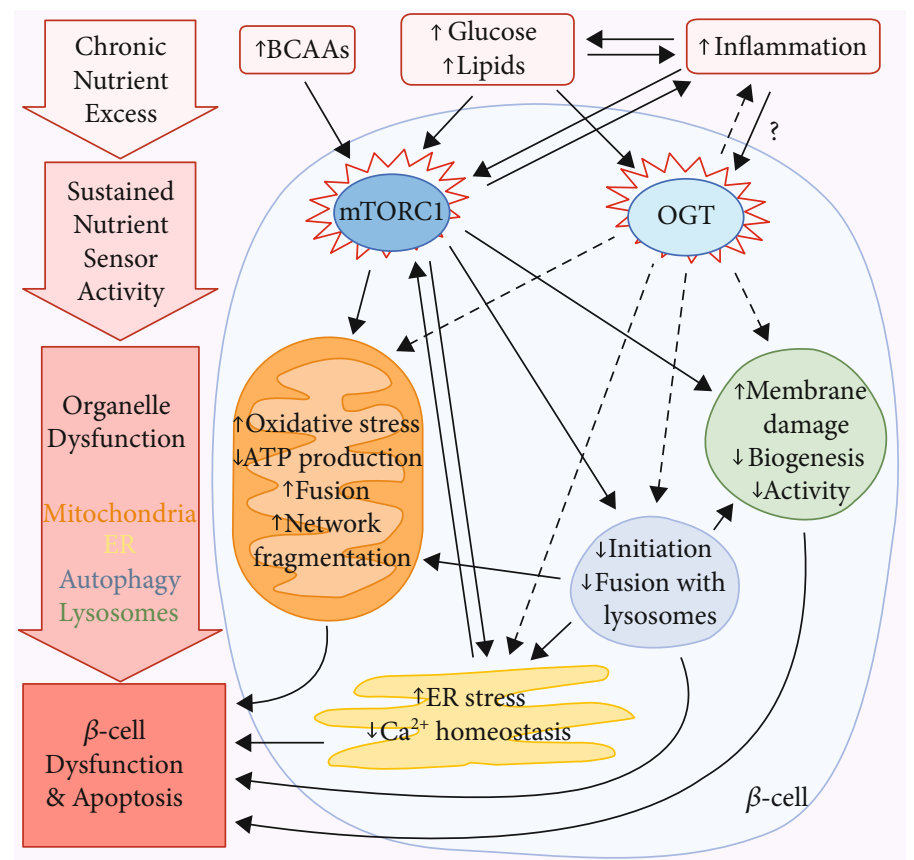

FIGURE 1: The pathology of $\beta$-cell dysfunction and failure during chronic nutrient excess: schematic summary of organelle dysfunction driven by dysregulated activity of mTORC1 and OGT. Type 2 diabetes (T2D) and obesity are characterized by chronically elevated hyperglycemia, hyperlipidemia, and elevations in branched-chain amino acids (BCAAs) and inflammation. These conditions activate two key intracellular nutrient sensors in $\beta$-cells: mechanistic target of rapamycin complex 1 (mTORC1) and O-linked N-acetylglucosamine transferase (OGT). Sustained activity of either of these nutrient sensors leads to comprehensive organelle dysfunction in $\beta$-cells. mTORC1 activity induces mitochondrial oxidative stress, impairs ATP production, and induces morphological and networking changes that disrupt mitochondrial health and function. In the endoplasmic reticulum (ER), mTORC1 hyperactivity causes ER stress, which can reinforce mTORC1 activity in positive feedback. mTORC1 suppresses autophagosome formation and fusion with lysosomes, which can impact the homeostasis of other organelles such as the mitochondria and ER. mTORC1 hyperactivity also induces lysosomal membrane damage, reduces biogenesis, and impairs the activity of lysosomal enzymes. mTORC1 also has a bidirectional relationship with inflammation that can strengthen these upstream signals. Published studies of increased OGT activity in $\beta$-cells during T2D have been more limited, but OGT generally follows similar patterns to mTORC1 in terms of its effects on organelle function. As the mitochondria, ER, autophagy, and lysosomes are each critical to the activities within $\beta$-cells, disruption of mTORC1 and OGT signaling leads to $\beta$-cell dysfunction and, if sustained, $\beta$-cell apoptosis. Black arrow: promotes indicated organelle dysfunction; dotted arrow: appears to promote indicated organelle dysfunction in some but not all contexts.

acinar cells during acute pancreatitis [287]. The ongoing exposure to a hyperglycemic state and the activation of NF$\kappa \mathrm{B}$ by mTOR and OGT may therefore contribute to the maintenance of chronic inflammation in islets and the progression of T2D.

6.2. Macrophages and $I L-1 \beta$. NF- $\kappa \mathrm{B}$ aids in the localization and activation of macrophages at sites of inflammation where they recruit additional immune cells, remove pathogens, and clear cellular debris $[278,288]$. Macrophages are a primary source of proinflammatory cytokines in the islet, with IL-1 $\beta$ being a key cytokine promoting $\beta$-cell dysfunction [267]. $\mathrm{NF}-\kappa \mathrm{B}$ regulates monocyte differentiation into M1 or M2 macrophages, which have pro- and anti-inflammatory phenotypes, respectively [289]. Islets treated with glucolipotoxic conditions demonstrate increased chemokine production [290]. Chronic hyperglycemia and obesity have been observed to promote the development and recruitment of macrophages with a proinflammatory phenotype in other tissues [276, 291]. Activation of the M1 phenotype is favored in the setting of islet inflammation in diabetic mouse models and contributes to $\beta$-cell dysfunction [292]. Once activated, islet macrophages produce IL- $1 \beta$ and TNF- $\alpha$, which act on the $\beta$-cell to further promote the production of chemokines and additional macrophage recruitment in an autostimulatory manner [293, 294]. Importantly, suppression of M1 macrophage recruitment to islets of $d b / d b$ mice improves glucose tolerance and GSIS [293]. By contrast, M2 macrophages appear to mediate $\beta$-cell proliferation [295].

Elevated IL-1 $\beta$ has been shown to be involved in impaired insulin secretion and insulin resistance [296]. Human islets secrete IL- $1 \beta$ in response to chronic hyperglycemia, promoting NF- $\kappa \mathrm{B}$ activation, differentiation of macrophages to the M1 phenotype, and contributing to islet inflammation that reduces insulin secretion [297]. There is evidence that hyperglycemia, ER stress, and oxidative stress induce IL- $1 \beta$ secretion from $\beta$-cells and macrophages through activation of the NLRP3 inflammasome [298, 299]. Inflammasome complexes are involved in the processing of IL-1 and IL-18 to their active forms via activation of caspase 1 , and upregulation of the NLRP3 inflammasome has been observed in T2D patients [300]. IL- $1 \beta$ is also able to stimulate its own expression in an autocrine fashion due to the high expression of the IL- 1 receptor on the $\beta$-cell membrane 
[301]. HFD-fed rats treated with an IL-1 receptor antagonist show improvements in hyperglycemia, islet insulin biosynthesis, insulin sensitivity, and decreased macrophage islet infiltration [302]. IL-1 $\beta$ also links hyperglycemia to $\beta$-cell apoptosis by increasing $\beta$-cell expression of the FAS receptor in response to high glucose conditions, which promotes the extrinsic apoptotic pathway when stimulated [297, 303].

6.3. Inflammation and $\beta$-Cell Stress. $\beta$-cells are sensitive to damage evoked by immune system responses and proinflammatory cytokines elevated during chronic inflammation mediate several modes of organelle dysfunction in $\beta$-cells $[264,268]$. Chronic treatment of $\beta$-cells with IL- $1 \beta$ increases the expression of inducible nitric oxide synthase (iNOS) [304], which is mediated by NF- $\kappa$ B [281], further increasing the expression of proinflammatory genes [304]. Cytokineinduced NO synthesis decreases SERCA2b expression and depletes ER calcium, leading to ER stress [305]. Activation of the UPR promotes further expression of TNF- $\alpha$, IL- $1 \beta$, and IL-6 [306, 307]. One important mediator between ER stress and inflammation in $\beta$-cells is thioredoxininteracting protein (TXNIP), which is activated by the IRE1 and PERK branches of the UPR and stimulates IL- $1 \beta$ transcription which ultimately promotes apoptosis via NLRP3 activation [308]. Sustained cytokine treatment also promotes ER stress-mediated $\beta$-cell apoptosis through activation of death protein 5 [309] and upregulation of miRNAs that regulate CHOP [310]. Pharmacological remediation of $\beta$-cell ER stress has been found to be protective against IL- $1 \beta$ induced apoptosis, further highlighting this connection [311]. Increased NO induced by IL- $1 \beta$ also reduces mitochondrial ATP synthesis [304], disrupting insulin secretion [312]. Furthermore, cytokine treatment induces mitochondrial network fragmentation and swelling [244]. ER stress-induced by cytokine stimulation of INS-1E cells and rat islets initiates autophagy [244], which may act as a protective mechanism against inflammation-induced $\beta$-cell dysfunction. Despite increased initiation, cytokines impair autophagic flux by promoting lysosomal alkalization and LMP [244]. Inflammation has broad effects on organelle function, but studies specific to $\beta$-cells are warranted given the chronic inflammation associated with T2D.

\section{Concluding Remarks}

The ER, mitochondria, lysosomes, and autophagosomes are fundamental regulators of $\beta$-cell function and an increasing number of reports highlight their role in glucolipotoxic and proinflammatory conditions in T2D. Chronic exposure to nutrients and proinflammatory cytokines during T2D promotes organelle dysfunction that contributes to $\beta$-cell dysfunction and the progression of T2D. Nutrient-sensing pathways are major regulators of organelle homeostasis. In general, acute activation of mTOR and OGT enhances organelle function in response to nutrient elevations. However, dysregulated activity driven by chronic nutrient excess and inflammation during T2D leads to profound changes in the ability of $\beta$-cell organelles to fulfill their roles (Figure 1). Beyond merely affecting organelle function,
mTORC1 and OGT hyperactivity can nudge organelles toward initiating proapoptotic pathways that enhance $\beta$-cell death during T2D. Inflammation enhances apoptotic signals induced by organelle dysfunction in $\beta$-cells, and the inflammatory process is regulated by mTOR and OGT. However, our knowledge on the roles of these nutrient sensors is evolving and in need of further research. There are many studies that examine mTORC1 hyperactivity and $\beta$-cell function and many that demonstrate the role of mTORC1 in ER, mitochondrial, lysosomal, and autophagic function and dysfunction. However, there are relatively few that link mTORC1 hyperstimulation during T2D to organelles within the $\beta$-cells specifically. There is a similar case for OGT, but this nutrient sensor has been studied even less in $\beta$-cells than mTOR. Additional studies in these areas are critical for understanding $\beta$-cell physiology and pathology during T2D. Antidiabetic medications such as GLP1-receptor agonists have been shown to improve $\beta$-cell function by restoring organelle homeostasis [313]. These molecules can help mitigate ER stress [314-316], improve mitochondrial performance $[317,318]$, and restore lysosomal function and autophagic flux under glucolipotoxic conditions [319]. However, despite the fact that mTORC1 or OGT broadly regulates many parameters of $\beta$-cell organelle homeostasis, therapeutics targeting these nutrient sensors in $\beta$-cells have not been developed. Molecular inhibitors have been identified for mTORC1 [320-322] and OGT [323-325], though many of these putative therapeutics have not been tested in the context of T2D. However, it has been suggested that intermittent dosing with rapamycin can preserve $\beta$-cell function and glucose homeostasis, which are negatively impacted by sustained rapamycin exposure [326, 327]. This treatment regimen has not been applied to humans, and its specific impacts on $\beta$-cells need to be further explored, but it may be a promising approach. Advancing our understanding of how nutrient sensors function within $\beta$-cells will allow better development and assessment of therapies and treatments for $\beta$-cell dysfunction during T2D and will therefore help mitigate the accelerating burden of this disease on nations and individuals.

\section{Conflicts of Interest}

The authors declare that they have no conflicts of interest.

\section{Acknowledgments}

This work was supported by the National Institutes of Health Grant NIDDK (R21DK112144 and R01DK115720 to EUA and T32DK108733 to MM). The authors apologize to all scientists whose important contributions were not referenced in this review owing to space limitations.

\section{References}

[1] A. B. Olokoba, O. A. Obateru, and L. B. Olokoba, "Type 2 diabetes mellitus: a review of current trends," Oman Medical Journal, vol. 27, no. 4, pp. 269-273, 2012. 
[2] A. D. Mooradian, "Dyslipidemia in type 2 diabetes mellitus," Nature Clinical Practice. Endocrinology \& Metabolism, vol. 5, no. 3, pp. 150-159, 2009.

[3] A. Gonzalez-Franquesa, A. M. Burkart, E. Isganaitis, and M. E. Patti, "What have metabolomics approaches taught us about type 2 diabetes?," Current Diabetes Reports, vol. 16, no. 8, p. 74, 2016.

[4] E. U. Alejandro, B. Gregg, M. Blandino-Rosano, C. CrasMeneur, and E. Bernal-Mizrachi, "Natural history of betacell adaptation and failure in type 2 diabetes," Molecular Aspects of Medicine, vol. 42, pp. 19-41, 2015.

[5] M. Prentki, M. L. Peyot, P. Masiello, and S. R. M. Madiraju, "Nutrient-induced metabolic stress, adaptation, detoxification, and toxicity in the pancreatic $\beta$-Cell," Diabetes, vol. 69, no. 3, pp. 279-290, 2020.

[6] Y. Tuo and M. Xiang, "mTOR: a double-edged sword for diabetes," Journal of Leukocyte Biology, vol. 106, no. 2, 2018.

[7] E. U. Alejandro, N. Bozadjieva, D. Kumusoglu et al., "Disruption of O-linked $\mathrm{N}$-acetylglucosamine signaling induces ER stress and beta cell failure," Cell Reports, vol. 13, pp. 25272538, 2015.

[8] T. Brun, C. Jiménez-Sánchez, J. G. S. Madsen et al., “AMPK profiling in rodent and human pancreatic beta-cells under nutrient-rich metabolic stress," International Journal of Molecular Sciences, vol. 21, 2020.

[9] T. Szkudelski and K. Szkudelska, "The relevance of AMPactivated protein kinase in insulin-secreting beta cells: a potential target for improving beta cell function?," Journal of Physiology and Biochemistry, vol. 75, pp. 423-432, 2019.

[10] S. Tsalamandris, A. S. Antonopoulos, E. Oikonomou et al., "The role of inflammation in diabetes: current concepts and future perspectives," European Cardiology Review, vol. 14, no. 1, pp. 50-59, 2019.

[11] F. Boutouja, C. M. Stiehm, and H. W. Platta, "mTOR: a cellular regulator interface in health and disease," Cell, vol. 8, no. 1, p. 18, 2019.

[12] G. C. Chau, D. U. Im, T. M. Kang et al., "mTOR controls ChREBP transcriptional activity and pancreatic beta cell survival under diabetic stress," The Journal of Cell Biology, vol. 216, no. 7, pp. 2091-2105, 2017.

[13] E. U. Alejandro, N. Bozadjieva, M. Blandino-Rosano et al., "Overexpression of kinase-dead mTOR impairs glucose homeostasis by regulating insulin secretion and not $\beta$-cell mass," Diabetes, vol. 66, no. 8, pp. 2150-2162, 2017.

[14] M. Blandino-Rosano, R. Barbaresso, M. Jimenez-Palomares et al., "Loss of mTORC1 signalling impairs beta-cell homeostasis and insulin processing," Nature Communications, vol. 8, no. 1, article 16014, 2017.

[15] Q. Ni, Y. Gu, Y. Xie et al., "Raptor regulates functional maturation of murine beta cells," Nature Communications, vol. 8, article 15755, 2017.

[16] L. Rachdi, N. Balcazar, F. Osorio-Duque et al., "Disruption of Tsc2 in pancreatic $\{$ beta $\}$ cells induces $\{$ beta $\}$ cell mass expansion and improved glucose tolerance in a TORC1-dependent manner," Proceedings of the National Academy of Sciences, vol. 105, no. 27, pp. 9250-9255, 2008.

[17] S. Hamada, K. Hara, T. Hamada et al., "Upregulation of the mammalian target of rapamycin complex 1 pathway by Ras homolog enriched in brain in pancreatic beta-cells leads to increased beta-cell mass and prevention of hyperglycemia," Diabetes, vol. 58, no. 6, pp. 1321-1332, 2009.
[18] Y. Gu, J. Lindner, A. Kumar, W. Yuan, and M. A. Magnuson, "Rictor/mTORC2 is essential for maintaining a balance between \{beta\}-cell proliferation and cell size," Diabetes, vol. 60, no. 3, pp. 827-837, 2011.

[19] R. Jaafar, S. Tran, A. N. Shah et al., "mTORC1 to AMPK switching underlies beta-cell metabolic plasticity during maturation and diabetes," The Journal of Clinical Investigation, vol. 129, no. 10, pp. 4124-4137, 2019.

[20] A. Helman, A. L. Cangelosi, J. C. Davis et al., “A nutrientsensing transition at birth triggers glucose-responsive insulin secretion," Cell Metabolism, vol. 31, no. 5, pp. 1004-1016 e1005, 2020.

[21] S. Vernier, A. Chiu, J. Schober et al., "Beta-cell metabolic alterations under chronic nutrient overload in rat and human islets," Islets, vol. 4, no. 6, pp. 379-392, 2012.

[22] A. Bartolome, M. Kimura-Koyanagi, S.-I. Asahara et al., "Pancreatic beta-cell failure mediated by mTORC1 hyperactivity and autophagic impairment," Diabetes, vol. 63, no. 9, pp. 2996-3008, 2014.

[23] A. Ardestani, B. Lupse, Y. Kido, G. Leibowitz, and K. Maedler, "mTORC1 signaling: a double-edged sword in diabetic beta cells," Cell Metabolism, vol. 27, pp. 314-331, 2018.

[24] T. Yuan, B. Lupse, K. Maedler, and A. Ardestani, "mTORC2 signaling: a path for pancreatic beta cell's growth and function," Journal of Molecular Biology, vol. 430, pp. 904-918, 2018.

[25] T. Yuan, S. Rafizadeh, K. D. D. Gorrepati et al., "Reciprocal regulation of mTOR complexes in pancreatic islets from humans with type 2 diabetes," Diabetologia, vol. 60, pp. 668-678, 2017.

[26] J. Kim and K. L. Guan, "mTOR as a central hub of nutrient signalling and cell growth," Nature Cell Biology, vol. 21, pp. 63-71, 2019.

[27] B. C. Melnik, "Leucine signaling in the pathogenesis of type 2 diabetes and obesity," World Journal of Diabetes, vol. 3, no. 3, pp. 38-53, 2012.

[28] G. Filhoulaud, G. Guillemain, and R. Scharfmann, "The hexosamine biosynthesis pathway is essential for pancreatic beta cell development," The Journal of Biological Chemistry, vol. 284, no. 36, pp. 24583-24594, 2009.

[29] N. L. Vanderford, S. S. Andrali, and S. Ozcan, "Glucose induces MafA expression in pancreatic beta cell lines via the hexosamine biosynthetic pathway," The Journal of Biological Chemistry, vol. 282, no. 3, pp. 1577-1584, 2007.

[30] K. W. Moremen, M. Tiemeyer, and A. V. Nairn, "Vertebrate protein glycosylation: diversity, synthesis and function," Nature Reviews. Molecular Cell Biology, vol. 13, no. 7, pp. 448-462, 2012.

[31] G. W. Hart, C. Slawson, G. Ramirez-Correa, and O. Lagerlof, "Cross talk between O-GlcNAcylation and phosphorylation: roles in signaling, transcription, and chronic disease," Annual Review of Biochemistry, vol. 80, pp. 825-858, 2011.

[32] M. R. Martinez, T. B. Dias, P. S. Natov, and N. E. Zachara, "Stress-induced O-GlcNAcylation: an adaptive process of injured cells," Biochemical Society Transactions, vol. 45, pp. 237-249, 2017.

[33] J. A. Hanover, Z. Lai, G. Lee, W. A. Lubas, and S. M. Sato, "Elevated O-linked N-acetylglucosamine metabolism in pancreatic beta-cells," Archives of Biochemistry and Biophysics, vol. 362, pp. 38-45, 1999. 
[34] S. Ida, K. Morino, O. Sekine et al., "Diverse metabolic effects of O-GlcNAcylation in the pancreas but limited effects in insulin-sensitive organs in mice," Diabetologia, vol. 60, pp. 1761-1769, 2017.

[35] M. D. Roos, W. Xie, K. Su et al., "Streptozotocin, an ana$\log$ of $\mathrm{N}$-acetylglucosamine, blocks the removal of $\mathrm{O}$ GlcNAc from intracellular proteins," Proceedings of the Association of American Physicians, vol. 110, pp. 422432, 1998.

[36] D. M. Lehman, D.-J. Fu, A. B. Freeman et al., "A single nucleotide polymorphism in MGEA5 encoding O-GlcNAcselective $\mathrm{N}$-acetyl- $\beta$-D glucosaminidase is associated with type 2 diabetes in Mexican Americans," Diabetes, vol. 54, pp. 1214-1221, 2005.

[37] V. S. Farook, C. Bogardus, and M. Prochazka, "Analysis of MGEA5 on 10q24.1-q24.3 encoding the $\beta$-O-linked $\mathrm{N}$ acetylglucosaminidase as a candidate gene for type 2 diabetes mellitus in Pima Indians," Molecular Genetics and Metabolism, vol. 77, pp. 189-193, 2002.

[38] Y. Akimoto, G. W. Hart, L. Wells et al., "Elevation of the post-translational modification of proteins by O-linked $\mathrm{N}$ acetylglucosamine leads to deterioration of the glucosestimulated insulin secretion in the pancreas of diabetic Goto-Kakizaki rats," Glycobiology, vol. 17, no. 2, pp. 127140, 2007.

[39] A. Lockridge, S. Jo, E. Gustafson et al., "Islet OGlcNAcylation is required for lipid potentiation of insulin secretion through SERCA2," Cell Reports, vol. 31, no. 5, article 107609, 2020.

[40] M. Liu, M. A. Weiss, A. Arunagiri et al., "Biosynthesis, structure, and folding of the insulin precursor protein," Diabetes, Obesity \& Metabolism, vol. 20, Suppl 2, pp. 2850, 2018.

[41] C. Hetz, "The unfolded protein response: controlling cell fate decisions under ER stress and beyond," Nature Reviews. Molecular Cell Biology, vol. 13, pp. 89-102, 2012.

[42] K. A. Moore and J. Hollien, "The unfolded protein response in secretory cell function," Annual Review of Genetics, vol. 46, pp. 165-183, 2012.

[43] R. B. Sharma, A. C. O’Donnell, R. E. Stamateris et al., "Insulin demand regulates beta cell number via the unfolded protein response," The Journal of Clinical Investigation, vol. 125, no. 10, pp. 3831-3846, 2015.

[44] M. Calfon, H. Zeng, F. Urano et al., "IRE1 couples endoplasmic reticulum load to secretory capacity by processing the XBP-1 mRNA," Nature, vol. 415, pp. 92-96, 2002.

[45] A. H. Lee, N. N. Iwakoshi, and L. H. Glimcher, "XBP-1 regulates a subset of endoplasmic reticulum resident chaperone genes in the unfolded protein response," Molecular and Cellular Biology, vol. 23, pp. 7448-7459, 2003.

[46] H. Nishitoh, M. Saitoh, Y. Mochida et al., "ASK1 is essential for JNK/SAPK activation by TRAF2," Molecular Cell, vol. 2, pp. 389-395, 1998.

[47] J. R. Hassler, D. L. Scheuner, S. Wang et al., "The IRE1alpha/XBP1s pathway is essential for the glucose response and protection of beta cells," PLoS Biology, vol. 13, article e1002277, 2015.

[48] P. Pirot, N. Naamane, F. Libert et al., "Global profiling of genes modified by endoplasmic reticulum stress in pancreatic beta cells reveals the early degradation of insulin mRNAs," Diabetologia, vol. 50, pp. 1006-1014, 2007.
[49] K. L. Lipson, R. Ghosh, and F. Urano, "The role of IRE1alpha in the degradation of insulin mRNA in pancreatic beta-cells," PLoS One, vol. 3, article e1648, 2008.

[50] H. P. Harding, Y. Zhang, A. Bertolotti, H. Zeng, and D. Ron, "Perk is essential for translational regulation and cell survival during the unfolded protein response," Molecular Cell, vol. 5, pp. 897-904, 2000.

[51] K. M. Vattem and R. C. Wek, "Reinitiation involving upstream ORFs regulates ATF4 mRNA translation in mammalian cells," Proceedings of the National Academy of Sciences of the United States of America, vol. 101, pp. 11269-11274, 2004.

[52] H. P. Harding, I. Novoa, Y. Zhang et al., "Regulated translation initiation controls stress-induced gene expression in mammalian cells," Molecular Cell, vol. 6, pp. 1099-1108, 2000.

[53] K. Haze, H. Yoshida, H. Yanagi, T. Yura, and K. Mori, "Mammalian transcription factor ATF6 is synthesized as a transmembrane protein and activated by proteolysis in response to endoplasmic reticulum stress," Molecular Biology of the Cell, vol. 10, pp. 3787-3799, 1999.

[54] H. Yoshida, T. Okada, K. Haze et al., "ATF6 activated by proteolysis binds in the presence of NF-Y (CBF) directly to the cis-acting element responsible for the mammalian unfolded protein response," Molecular and Cellular Biology, vol. 20, pp. 6755-6767, 2000.

[55] H.-Y. Seo, Y. D. Kim, K.-M. Lee et al., "Endoplasmic reticulum stress-induced activation of activating transcription factor 6 decreases insulin gene expression via up-regulation of orphan nuclear receptor small heterodimer partner," Endocrinology, vol. 149, pp. 3832-3841, 2008.

[56] F. Engin, A. Yermalovich, T. Nguyen et al., "Restoration of the unfolded protein response in pancreatic beta cells protects mice against type 1 diabetes," Science Translational Medicine, vol. 5, p. 211ra156, 2013.

[57] F. Dingreville, B. Panthu, C. Thivolet et al., "Differential effect of glucose on ER-mitochondria $\mathrm{ca}(2+)$ exchange participates in insulin secretion and glucotoxicity-mediated dysfunction of beta-cells," Diabetes, vol. 68, pp. 1778-1794, 2019.

[58] D. A. Cunha, P. Hekerman, L. Ladriere et al., "Initiation and execution of lipotoxic ER stress in pancreatic beta-cells," Journal of Cell Science, vol. 121, no. 14, pp. 2308-2318, 2008.

[59] C. D. Green and L. K. Olson, "Modulation of palmitateinduced endoplasmic reticulum stress and apoptosis in pancreatic beta-cells by stearoyl-CoA desaturase and Elovl6," American Journal of Physiology. Endocrinology and Metabolism, vol. 300, no. 4, pp. E640-E649, 2011.

[60] A. M. Preston, E. Gurisik, C. Bartley, D. R. Laybutt, and T. J. Biden, "Reduced endoplasmic reticulum (ER)-to-Golgi protein trafficking contributes to ER stress in lipotoxic mouse beta cells by promoting protein overload," Diabetologia, vol. 52, pp. 2369-2373, 2009.

[61] C. Colombo, O. Porzio, M. Liu et al., "Seven mutations in the human insulin gene linked to permanent neonatal/infancyonset diabetes mellitus," The Journal of Clinical Investigation, vol. 118, pp. 2148-2156, 2008.

[62] C. Julier and M. Nicolino, "Wolcott-Rallison syndrome," Orphanet Journal of Rare Diseases, vol. 5, p. 29, 2010.

[63] S. Liu, G. Ma, S. Yao et al., "Polymorphism $-116 \mathrm{C} / \mathrm{G}$ of the human $\mathrm{X}$ box binding protein 1 gene is associated with risk 
of type 2 diabetes in a Chinese Han population," Gene, vol. 575, pp. 71-74, 2016.

[64] F. Thameem, V. S. Farook, C. Bogardus, and M. Prochazka, "Association of amino acid variants in the activating transcription factor 6 gene (ATF6) on 1q21-q23 with type 2 diabetes in Pima Indians," Diabetes, vol. 55, pp. 839-842, 2006.

[65] S. J. R. Meex, M. M. J. van Greevenbroek, T. A. Ayoubi et al., "Activating transcription factor 6 polymorphisms and haplotypes are associated with impaired glucose homeostasis and type 2 diabetes in Dutch Caucasians," The Journal of Clinical Endocrinology and Metabolism, vol. 92, pp. 2720-2725, 2007.

[66] D. R. Laybutt, A. M. Preston, M. C. Åkerfeldt et al., "Endoplasmic reticulum stress contributes to beta cell apoptosis in type 2 diabetes," Diabetologia, vol. 50, pp. 752-763, 2007.

[67] P. Marchetti, M. Bugliani, R. Lupi et al., "The endoplasmic reticulum in pancreatic beta cells of type 2 diabetes patients," Diabetologia, vol. 50, pp. 2486-2494, 2007.

[68] C.-j. Huang, C.-y. Lin, L. Haataja et al., "High expression rates of human islet amyloid polypeptide induce endoplasmic reticulum stress mediated $\beta$-cell apoptosis, a characteristic of humans with type 2 but not type 1 diabetes," Diabetes, vol. 56, pp. 2016-2027, 2007.

[69] S. Negi, S. H. Park, A. Jetha, R. Aikin, M. Tremblay, and S. Paraskevas, "Evidence of endoplasmic reticulum stress mediating cell death in transplanted human islets," Cell Transplantation, vol. 21, pp. 889-900, 2012.

[70] D. Scheuner, D. V. Mierde, B. Song et al., "Control of mRNA translation preserves endoplasmic reticulum function in beta cells and maintains glucose homeostasis," Nature Medicine, vol. 11, pp. 757-764, 2005.

[71] B. Song, D. Scheuner, D. Ron, S. Pennathur, and R. J. Kaufman, "Chop deletion reduces oxidative stress, improves beta cell function, and promotes cell survival in multiple mouse models of diabetes," The Journal of Clinical Investigation, vol. 118, pp. 3378-3389, 2008.

[72] C. Appenzeller-Herzog and M. N. Hall, "Bidirectional crosstalk between endoplasmic reticulum stress and mTOR signaling," Trends in Cell Biology, vol. 22, pp. 274-282, 2012.

[73] J. Wang, X. Yang, and J. Zhang, "Bridges between mitochondrial oxidative stress, ER stress and mTOR signaling in pancreatic $\beta$ cells," Cellular Signalling, vol. 28, pp. 1099-1104, 2016.

[74] D. Allen and J. Seo, "ER stress activates the TOR pathway through Atf6," Journal of Molecular Signaling, vol. 13, p. 1, 2018.

[75] C.-H. Chen, T. Shaikenov, T. R. Peterson et al., "ER stress inhibits mTORC2 and Akt signaling through GSK-3betamediated phosphorylation of rictor," Science Signaling, vol. 4, p. ra10, 2011.

[76] S. Asahara, T. Matsuda, Y. Kido, and M. Kasuga, "Increased ribosomal biogenesis induces pancreatic beta cell failure in mice model of type 2 diabetes," Biochemical and Biophysical Research Communications, vol. 381, pp. 367-371, 2009.

[77] M. Bugliani, S. Mossuto, F. Grano et al., "Modulation of autophagy influences the function and survival of human pancreatic beta cells under endoplasmic reticulum stress conditions and in type 2 diabetes," Frontiers in Endocrinology, vol. 10, p. 52, 2019.

[78] J. D. Wikstrom, T. Israeli, E. Bachar-Wikstrom et al., "AMPK regulates ER morphology and function in stressed pancreatic beta-cells via phosphorylation of DRP1," Molecular Endocrinology, vol. 27, pp. 1706-1723, 2013.

[79] E. Bachar-Wikstrom, J. D. Wikstrom, Y. Ariav et al., "Stimulation of autophagy improves endoplasmic reticulum stressinduced diabetes," Diabetes, vol. 62, pp. 1227-1237, 2013.

[80] E. Bachar, Y. Ariav, M. Ketzinel-Gilad, E. Cerasi, N. Kaiser, and G. Leibowitz, "Glucose amplifies fatty acid-induced endoplasmic reticulum stress in pancreatic beta-cells via activation of mTORC1," PLoS One, vol. 4, p. e4954, 2009.

[81] Z. V. Wang, Y. Deng, N. Gao et al., "Spliced X-box binding protein 1 couples the unfolded protein response to hexosamine biosynthetic pathway," Cell, vol. 156, pp. 1179-1192, 2014.

[82] A. T. Sage, L. A. Walter, Y. Shi et al., "Hexosamine biosynthesis pathway flux promotes endoplasmic reticulum stress, lipid accumulation, and inflammatory gene expression in hepatic cells," American Journal of Physiology. Endocrinology and Metabolism, vol. 298, pp. E499-E511, 2010.

[83] A. T. Sage, L. A. Walter, Y. Shi et al., "Glucosamine-induced endoplasmic reticulum dysfunction is associated with accelerated atherosclerosis in a hyperglycemic mouse model," Diabetes, vol. 55, pp. 93-101, 2006.

[84] V. Chesnokov, B. Gong, C. Sun, and K. Itakura, "Anti-cancer activity of glucosamine through inhibition of N-linked glycosylation," Cancer Cell International, vol. 14, no. 1, p. 45, 2014.

[85] R. A. Reeves, A. Lee, R. Henry, and N. E. Zachara, "Characterization of the specificity of O-GlcNAc reactive antibodies under conditions of starvation and stress," Analytical Biochemistry, vol. 457, pp. 8-18, 2014.

[86] G. A. Ngoh, T. Hamid, S. D. Prabhu, and S. P. Jones, "OGlcNAc signaling attenuates ER stress-induced cardiomyocyte death," American Journal of Physiology. Heart and Circulatory Physiology, vol. 297, pp. H1711-H1719, 2009.

[87] C. M. Ferrer, T. P. Lynch, V. L. Sodi et al., "O-GlcNAcylation regulates cancer metabolism and survival stress signaling via regulation of the HIF-1 pathway," Molecular Cell, vol. 54, pp. 820-831, 2014.

[88] H. N. Suh, Y. J. Lee, M. O. Kim, J. M. Ryu, and H. J. Han, "Glucosamine-induced Sp1 O-GlcNAcylation ameliorates hypoxia-induced SGLT dysfunction in primary cultured renal proximal tubule cells," Journal of Cellular Physiology, vol. 229, pp. 1557-1568, 2014.

[89] T. Ohn, N. Kedersha, T. Hickman, S. Tisdale, and P. Anderson, "A functional RNAi screen links O-GlcNAc modification of ribosomal proteins to stress granule and processing body assembly," Nature Cell Biology, vol. 10, pp. 1224-1231, 2008.

[90] I. Jang, H. B. Kim, H. Seo et al., "O-GlcNAcylation of eIF2alpha regulates the phospho-eIF2alpha-mediated ER stress response," Biochimica et Biophysica Acta, vol. 1853, no. 8, pp. 1860-1869, 2015.

[91] O. Blondel, J. Takeda, H. Janssen, S. Seino, and G. I. Bell, "Sequence and functional characterization of a third inositol trisphosphate receptor subtype, IP3R-3, expressed in pancreatic islets, kidney, gastrointestinal tract, and other tissues," The Journal of Biological Chemistry, vol. 268, 1993.

[92] P. Bimboese, C. J. Gibson, S. Schmidt, W. Xiang, and B. E. Ehrlich, "Isoform-specific regulation of the inositol 1,4,5-trisphosphate receptor by O-linked glycosylation," The Journal of Biological Chemistry, vol. 286, pp. 15688-15697, 2011. 
[93] M. Masini, L. Marselli, M. Bugliani et al., "Ultrastructural morphometric analysis of insulin secretory granules in human type 2 diabetes," Acta Diabetologica, vol. 49, Suppl 1, pp. S247-S252, 2012.

[94] Y. Xue, W. Zhao, W. Du et al., "Ultra-structural study of insulin granules in pancreatic $\beta$-cells of $\mathrm{db} / \mathrm{db}$ mouse by scanning transmission electron microscopy tomography," Protein \& Cell, vol. 3, pp. 521-525, 2012.

[95] O. H. Do, J. E. Gunton, H. Y. Gaisano, and P. Thorn, "Changes in beta cell function occur in prediabetes and early disease in the Lepr $(\mathrm{db})$ mouse model of diabetes," Diabetologia, vol. 59, pp. 1222-1230, 2016.

[96] X. Zhang, X. Peng, C. Han et al., “A unified deep-learning network to accurately segment insulin granules of different animal models imaged under different electron microscopy methodologies," Protein \& Cell, vol. 10, pp. 306-311, 2019.

[97] J. C. Hou, L. Min, and J. E. Pessin, "Insulin granule biogenesis, trafficking and exocytosis," Vitamins and Hormones, vol. 80, pp. 473-506, 2009.

[98] K. D. Jeffrey, E. U. Alejandro, D. S. Luciani et al., "Carboxypeptidase E mediates palmitate-induced beta-cell ER stress and apoptosis," Proceedings of the National Academy of Sciences of the United States of America, vol. 105, pp. 84528457, 2008.

[99] V. Marshansky and M. Futai, “The V-type H+-ATPase in vesicular trafficking: targeting, regulation and function," Current Opinion in Cell Biology, vol. 20, pp. 415-426, 2008.

[100] M. Lu, Y. Y. Sautin, L. S. Holliday, and S. L. Gluck, "The glycolytic enzyme aldolase mediates assembly, expression, and activity of vacuolar H+-ATPase," The Journal of Biological Chemistry, vol. 279, pp. 8732-8739, 2004.

[101] J. C. Trinidad, D. T. Barkan, B. F. Gulledge et al., "Global identification and characterization of both $\mathrm{O}$ GlcNAcylation and phosphorylation at the murine synapse," Molecular \& Cellular Proteomics, vol. 11, pp. 215-229, 2012.

[102] S. Wang, F. Yang, V. A. Petyuk et al., "Quantitative proteomics identifies altered O-GlcNAcylation of structural, synaptic and memory-associated proteins in Alzheimer's disease," The Journal of Pathology, vol. 243, pp. 78-88, 2017.

[103] S. Jo, A. Lockridge, and E. U. Alejandro, "eIF4G1 and carboxypeptidase $\mathrm{E}$ axis dysregulation in O-GlcNAc transferase-deficient pancreatic beta cells contributes to hyperproinsulinemia in mice," The Journal of Biological Chemistry, vol. 294, no. 35, pp. 13040-13050, 2019.

[104] K. E. Syring, K. J. Bosma, S. B. Goleva et al., "Potential positive and negative consequences of $\mathrm{ZnT} 8$ inhibition," The Journal of Endocrinology, vol. 246, pp. 189-205, 2020.

[105] N. Wijesekara, F. F. Dai, A. B. Hardy et al., "Beta cell-specific Znt8 deletion in mice causes marked defects in insulin processing, crystallisation and secretion," Diabetologia, vol. 53, pp. 1656-1668, 2010.

[106] K. L. Sinagoga, W. J. Stone, J. V. Schiesser et al., "Distinct roles for the mTOR pathway in postnatal morphogenesis, maturation and function of pancreatic islets," Development, vol. 144, pp. 2402-2414, 2017.

[107] J. K. Naggert, L. D. Fricker, O. Varlamov et al., "Hyperproinsulinaemia in obese fat/fat mice associated with a carboxypeptidase E mutation which reduces enzyme activity," Nature Genetics, vol. 10, pp. 135-142, 1995.

[108] O. Varlamov, L. D. Fricker, H. Furukawa, D. F. Steiner, S. H. Langley, and E. H. Leiter, " $\beta$-cell lines derived from trans- genic $\mathrm{Cpe} \mathrm{fat}^{\mathrm{fa}} / \mathrm{Cpe}^{\mathrm{fat}}$ mice are defective in carboxypeptidase $\mathrm{E}$ and proinsulin processing," Endocrinology, vol. 138, pp. 4883-4892, 1997.

[109] C. W. Liew, A. Assmann, A. T. Templin et al., "Insulin regulates carboxypeptidase $\mathrm{E}$ by modulating translation initiation scaffolding protein eIF4G1 in pancreatic beta cells," Proceedings of the National Academy of Sciences of the United States of America, vol. 111, pp. E2319-E2328, 2014.

[110] M. Blandino-Rosano, R. Barbaresso, M. Jimenez-Palomares et al., "Loss of mTORC1 signalling impairs $\beta$-cell homeostasis and insulin processing," Nature Communications, vol. 8, 2017.

[111] P. Rorsman and M. Braun, "Regulation of insulin secretion in human pancreatic islets," Annual Review of Physiology, vol. 75, no. 1, pp. 159-179, 2013.

[112] P. Maechler, "Mitochondrial function and insulin secretion," Molecular and Cellular Endocrinology, vol. 379, no. 1-2, pp. 12-18, 2013.

[113] T. Brun and P. Maechler, "Beta-cell mitochondrial carriers and the diabetogenic stress response," Biochimica et Biophysica Acta (BBA) - Molecular Cell Research, vol. 1863, pp. 2540-2549, 2016.

[114] M. Fex, L. M. Nicholas, N. Vishnu et al., "The pathogenetic role of $\beta$-cell mitochondria in type 2 diabetes," The Journal of Endocrinology, vol. 236, 2018.

[115] R. P. Robertson, "Chronic oxidative stress as a central mechanism for glucose toxicity in pancreatic islet beta cells in diabetes," The Journal of Biological Chemistry, vol. 279, no. 41, pp. 42351-42354, 2004.

[116] K. Meyerovich, F. Ortis, and A. K. Cardozo, “The noncanonical NF-kappaB pathway and its contribution to betacell failure in diabetes," Journal of Molecular Endocrinology, vol. 61, pp. F1-F6, 2018.

[117] H. Kaneto, Y. Nakatani, D. Kawamori, T. Miyatsuka, and T. A. Matsuoka, "Involvement of oxidative stress and the JNK pathway in glucose toxicity," The Review of Diabetic Studies, vol. 1, pp. 165-174, 2004.

[118] S. L. Gaffen, S. Y. Lai, M. Ha et al., "Distinct tyrosine residues within the interleukin-2 receptor beta chain drive signal transduction specificity, redundancy, and diversity," The Journal of Biological Chemistry, vol. 271, pp. 21381-21390, 1996.

[119] M. A. Modak, P. B. Parab, and S. S. Ghaskadbi, "Pancreatic islets are very poor in rectifying oxidative DNA damage," Pancreas, vol. 38, pp. 23-29, 2009.

[120] K. Sakai, K. Matsumoto, T. Nishikawa et al., "Mitochondrial reactive oxygen species reduce insulin secretion by pancreatic beta-cells," Biochemical and Biophysical Research Communications, vol. 300, pp. 216-222, 2003.

[121] N. Lameloise, P. Muzzin, M. Prentki, and F. AssimacopoulosJeannet, "Uncoupling protein 2: a possible link between fatty acid excess and impaired glucose-induced insulin secretion?," Diabetes, vol. 50, pp. 803-809, 2001.

[122] G. A. Martens, Y. Cai, S. Hinke, G. Stangé, M. Van de Casteele, and D. Pipeleers, "Glucose suppresses superoxide generation in metabolically responsive pancreatic beta cells," The Journal of Biological Chemistry, vol. 280, pp. 20389-20396, 2005.

[123] A. Sarre, J. Gabrielli, G. Vial, X. M. Leverve, and F. Assimacopoulos-Jeannet, "Reactive oxygen species are produced at low glucose and contribute to the activation of 
AMPK in insulin-secreting cells," Free Radical Biology \& Medicine, vol. 52, pp. 142-150, 2012.

[124] J. Gollmer, A. Zirlik, and H. Bugger, "Mitochondrial mechanisms in diabetic cardiomyopathy," Diabetes and Metabolism Journal, vol. 44, pp. 33-53, 2020.

[125] B. Van Houten, S. E. Hunter, and J. N. Meyer, "Mitochondrial DNA damage induced autophagy, cell death, and disease," Frontiers in Bioscience, vol. 21, pp. 42-54, 2016.

[126] M. Karbowski, C. Kurono, M. Wozniak et al., "Free radical-induced megamitochondria formation and apoptosis," Free Radical Biology \& Medicine, vol. 26, pp. 396409, 1999.

[127] R. Gredilla, "DNA damage and base excision repair in mitochondria and their role in aging," Journal of Aging Research, vol. 2011, Article ID 257093, 9 pages, 2010.

[128] S. Krauss, C. Y. Zhang, L. Scorrano et al., "Superoxide-mediated activation of uncoupling protein 2 causes pancreatic beta cell dysfunction," The Journal of Clinical Investigation, vol. 112, pp. 1831-1842, 2003.

[129] C.-Y. Zhang, G. Baffy, P. Perret et al., "Uncoupling protein-2 negatively regulates insulin secretion and is a major link between obesity, beta cell dysfunction, and type 2 diabetes," Cell, vol. 105, pp. 745-755, 2001.

[130] N.-G. Larsson, J. Wang, H. Wilhelmsson et al., "Mitochondrial transcription factor A is necessary for mtDNA maintenance and embryogenesis in mice," Nature Genetics, vol. 18, pp. 231-236, 1998.

[131] J. P. Silva, M. Köhler, C. Graff et al., "Impaired insulin secretion and $\beta$-cell loss in tissue-specific knockout mice with mitochondrial diabetes," Nature Genetics, vol. 26, pp. 336340, 2000.

[132] M. Anello, R. Lupi, D. Spampinato et al., "Functional and morphological alterations of mitochondria in pancreatic beta cells from type 2 diabetic patients," Diabetologia, vol. 48, no. 2, pp. 282-289, 2005.

[133] S. Del Guerra, R. Lupi, L. Marselli et al., "Functional and molecular defects of pancreatic islets in human type 2 diabetes," Diabetes, vol. 54, no. 3, pp. 725-735, 2005.

[134] R. Lupi, S. Del Guerra, R. Mancarella et al., "Insulin secretion defects of human type 2 diabetic islets are corrected in vitro by a new reactive oxygen species scavenger," Diabetes \& Metabolism, vol. 33, no. 5, pp. 340-345, 2007.

[135] Y. Ihara, S. Toyokuni, K. Uchida et al., "Hyperglycemia causes oxidative stress in pancreatic beta-cells of GK rats, a model of type 2 diabetes," Diabetes, vol. 48, no. 4, pp. 927932, 1999.

[136] H. Lu, V. Koshkin, E. M. Allister, A. V. Gyulkhandanyan, and M. B. Wheeler, "Molecular and metabolic evidence for mitochondrial defects associated with beta-cell dysfunction in a mouse model of type 2 diabetes," Diabetes, vol. 59, no. 2, pp. 448-459, 2010.

[137] V. P. Bindokas, A. Kuznetsov, S. Sreenan, K. S. Polonsky, M. W. Roe, and L. H. Philipson, "Visualizing superoxide production in normal and diabetic rat islets of Langerhans," The Journal of Biological Chemistry, vol. 278, no. 11, pp. 97969801, 2003.

[138] B. Tyrberg, K. A. Anachkov, S. A. Dib, J. Wang-Rodriguez, K.-H. Yoon, and F. Levine, "Islet expression of the DNA repair enzyme 8-oxoguanosine DNA glycosylase (Ogg1) in human type 2 diabetes," BMC Endocrine Disorders, vol. 2, no. $1,2002$.
[139] C. B. Chan, P. E. MacDonald, M. C. Saleh, D. C. Johns, E. Marban, and M. B. Wheeler, "Overexpression of uncoupling protein 2 inhibits glucose-stimulated insulin secretion from rat islets," Diabetes, vol. 48, pp. 1482-1486, 1999.

[140] C. B. Chan, P. E. MacDonald, M. C. Saleh, D. C. Johns, E. Marban, and M. B. Wheeler, "Mitochondrial dynamics and morphology in beta-cells," Best Practice \& Research. Clinical Endocrinology \& Metabolism, vol. 26, no. 6, pp. 725-738, 2012.

[141] F. Dingreville, B. Panthu, C. Thivolet et al., "Differential effect of glucose on ER-mitochondria ca 2+ exchange participates in insulin secretion and glucotoxicity-mediated dysfunction of $\beta$-cells," Diabetes, vol. 68, no. 9, pp. 1778-1794, 2019.

[142] M. Higa, Y.-T. Zhou, M. Ravazzola, D. Baetens, L. Orci, and R. H. Unger, "Troglitazone prevents mitochondrial alterations, beta cell destruction, and diabetes in obese prediabetic rats," Proceedings of the National Academy of Sciences of the United States of America, vol. 96, no. 20, pp. 11513-11518, 1999.

[143] A. Dlasková, T. Špaček, J. Šantorová et al., “4Pi microscopy reveals an impaired three-dimensional mitochondrial network of pancreatic islet beta-cells, an experimental model of type-2 diabetes," Biochimica et Biophysica Acta (BBA) - Bioenergetics, vol. 1797, no. 6-7, pp. 1327-1341, 2010.

[144] A. J. A. Molina, J. D. Wikstrom, L. Stiles et al., "Mitochondrial networking protects beta-cells from nutrient-induced apoptosis," Diabetes, vol. 58, no. 10, pp. 2303-2315, 2009.

[145] K.-S. Park, A. Wiederkehr, C. Kirkpatrick et al., "Selective actions of mitochondrial fission/fusion genes on metabolism-secretion coupling in insulin-releasing cells," The Journal of Biological Chemistry, vol. 283, no. 48, pp. 33347-33356, 2008.

[146] M. Morita, S.-P. Gravel, L. Hulea et al., "mTOR coordinates protein synthesis, mitochondrial activity and proliferation," Cell Cycle, vol. 14, pp. 473-480, 2015.

[147] M. Morita, S.-P. Gravel, V. Chénard et al., "mTORC1 controls mitochondrial activity and biogenesis through 4E-BPdependent translational regulation," Cell Metabolism, vol. 18, no. 5, pp. 698-711, 2013.

[148] P. Newsholme and M. Krause, "Nutritional regulation of insulin secretion: implications for diabetes," The Clinical Biochemist Reviews, vol. 33, no. 2, p. 35, 2012.

[149] M. Koyanagi, S.-i. Asahara, T. Matsuda et al., "Ablation of TSC2 enhances insulin secretion by increasing the number of mitochondria through activation of mTORC1," PLoS One, vol. 6, no. 8, article e23238, 2011.

[150] A. Bartolome, M. Kimura-Koyanagi, S.-I. Asahara et al., "Pancreatic $\beta$-cell failure mediated by mTORC1 hyperactivity and autophagic impairment," Diabetes, vol. 63, no. 9, pp. 2996-3008, 2014.

[151] M. Shimodahira, S. Fujimoto, E. Mukai et al., "Rapamycin impairs metabolism-secretion coupling in rat pancreatic islets by suppressing carbohydrate metabolism," The Journal of Endocrinology, vol. 204, no. 1, pp. 37-46, 2010.

[152] J. L. Sacoman, R. Y. Dagda, A. R. Burnham-Marusich, R. K. Dagda, and P. M. Berninsone, "Mitochondrial O-GlcNAc transferase (mOGT) regulates mitochondrial structure, function, and survival in HeLa cells," The Journal of Biological Chemistry, vol. 292, no. 11, pp. 4499-4518, 2017.

[153] P. S. Banerjee, J. Ma, and G. W. Hart, "Diabetes-associated dysregulation of O-GlcNAcylation in rat cardiac 
mitochondria," Proceedings of the National Academy of Sciences of the United States of America, vol. 112, pp. 60506055, 2015.

[154] T. Gawlowski, J. Suarez, B. Scott et al., "Modulation of dynamin-related protein 1 (DRP1) function by increased Olinked- $\beta$-N-acetylglucosamine modification (O-GlcNAc) in cardiac myocytes," The Journal of Biological Chemistry, vol. 287, no. 35, pp. 30024-30034, 2012.

[155] A. Makino, J. Suarez, T. Gawlowski et al., "Regulation of mitochondrial morphology and function by $\mathrm{O}$ GlcNAcylation in neonatal cardiac myocytes," American journal of physiology. Regulatory, Integrative and Comparative Physiology, vol. 300, no. 2, pp. R1296-R1302, 2011.

[156] J. Ma, T. Liu, A.-C. Wei, P. Banerjee, B. O'Rourke, and G. W. Hart, "O-GlcNAcomic profiling identifies widespread Olinked $\beta$-N-acetylglucosamine modification (O-GlcNAcylation) in oxidative phosphorylation system regulating cardiac mitochondrial function," The Journal of Biological Chemistry, vol. 290, no. 49, pp. 29141-29153, 2015.

[157] J. Ma, P. Banerjee, S. A. Whelan et al., "Comparative proteomics reveals dysregulated mitochondrial O-GlcNAcylation in diabetic hearts," Journal of Proteome Research, vol. 15, no. 7, pp. 2254-2264, 2016.

[158] E. P. Tan, M. T. Villar, E. Lezi et al., “Altering O-linked beta$\mathrm{N}$-acetylglucosamine cycling disrupts mitochondrial function," The Journal of Biological Chemistry, vol. 289, no. 21, pp. 14719-14730, 2014.

[159] J. Suarez, Y. Hu, A. Makino, E. Fricovsky, H. Wang, and W. H. Dillmann, "Alterations in mitochondrial function and cytosolic calcium induced by hyperglycemia are restored by mitochondrial transcription factor A in cardiomyocytes," American Journal of Physiology. Cell Physiology, vol. 295, no. 6, pp. C1561-C1568, 2008.

[160] F. Cividini, B. T. Scott, A. Dai et al., "O-GlcNAcylation of 8oxoguanine DNA glycosylase (Ogg1) impairs oxidative mitochondrial DNA lesion repair in diabetic hearts," The Journal of Biological Chemistry, vol. 291, no. 51, pp. 26515-26528, 2016.

[161] V. L. Johnsen, D. D. Belke, C. C. Hughey et al., "Enhanced cardiac protein glycosylation (O-GlcNAc) of selected mitochondrial proteins in rats artificially selected for low running capacity," Physiological Genomics, vol. 45, no. 1, pp. 17-25, 2013.

[162] E. P. Tan, S. R. McGreal, S. Graw et al., "Sustained O- GlcNAcylation reprograms mitochondrial function to regulate energy metabolism," The Journal of Biological Chemistry, vol. 292, no. 36, pp. 14940-14962, 2017.

[163] J. L. N. Wright, G. A. Benavides, M. S. Johnson et al., "Acute increases in O-GlcNAc indirectly impair mitochondrial bioenergetics through dysregulation of LonP1-mediated mitochondrial protein complex turnover," American Journal of Physiology-Cell Physiology, vol. 316, no. 6, pp. C862-C875, 2019.

[164] Y. Hu, J. Suarez, E. Fricovsky et al., "Increased enzymatic OGlcNAcylation of mitochondrial proteins impairs mitochondrial function in cardiac myocytes exposed to high glucose," The Journal of Biological Chemistry, vol. 284, no. 1, pp. 547-555, 2009.

[165] S. Dassanayaka, R. D. Readnower, J. K. Salabei et al., "High glucose induces mitochondrial dysfunction independently of protein O-GlcNAcylation," The Biochemical Journal, vol. 467, no. 1, pp. 115-126, 2015.
[166] V. V. Lima, K. Spitler, H. Choi, R. C. Webb, and R. C. Tostes, "O-GlcNAcylation and oxidation of proteins: is signalling in the cardiovascular system becoming sweeter?," Clinical Science, vol. 123, no. 8, pp. 473-486, 2012.

[167] H. Kaneto, G. Xu, K.-H. Song et al., "Activation of the hexosamine pathway leads to deterioration of pancreatic beta-cell function through the induction of oxidative stress," The Journal of Biological Chemistry, vol. 276, no. 33, pp. 31099-31104, 2001.

[168] C. Beall, K. Piipari, H. Al-Qassab et al., "Loss of AMPactivated protein kinase alpha2 subunit in mouse beta-cells impairs glucose-stimulated insulin secretion and inhibits their sensitivity to hypoglycaemia," The Biochemical Journal, vol. 429, no. 2, pp. 323-333, 2010.

[169] A. Swisa, Z. Granot, N. Tamarina et al., "Loss of liver kinase B1 (LKB1) in beta cells enhances glucose-stimulated insulin secretion despite profound mitochondrial defects," The Journal of Biological Chemistry, vol. 290, no. 34, pp. 20934-20946, 2015.

[170] Y. Cai, G. A. Martens, S. A. Hinke, H. Heimberg, D. Pipeleers, and M. Van de Casteele, "Increased oxygen radical formation and mitochondrial dysfunction mediate beta cell apoptosis under conditions of AMP-activated protein kinase stimulation," Free Radical Biology \& Medicine, vol. 42, pp. 64-78, 2007.

[171] W.-H. Kim, J. W. Lee, Y. H. Suh et al., “AICAR potentiates ROS production induced by chronic high glucose: roles of AMPK in pancreatic beta-cell apoptosis," Cellular Signalling, vol. 19, no. 4, pp. 791-805, 2007.

[172] D. W. Lamming and L. Bar-Peled, “The metabolic signaling hub," Traffic, vol. 20, no. 1, pp. 27-38, 2019.

[173] A. Goginashvili, Z. Zhang, E. Erbs et al., "Insulin granules. Insulin secretory granules control autophagy in pancreatic $\beta$ cells," Science, vol. 347, no. 6224, pp. 878-882, 2015.

[174] A. H. S. Landstrom, J. Westman, and L. A. H. Borg, "Lysosomes and pancreatic islet function. Time course of insulin biosynthesis, insulin secretion, and lysosomal transformation after rapid changes in glucose concentration," Diabetes, vol. 37, no. 3, pp. 309-316, 1988.

[175] B. Jaishy and E. D. Abel, "Lipids, lysosomes, and autophagy," Journal of Lipid Research, vol. 57, no. 9, pp. 1619-1635, 2016.

[176] A.-C. Johansson, H. Appelqvist, C. Nilsson, K. Kågedal, K. Roberg, and K. Öllingerc, "Regulation of apoptosisassociated lysosomal membrane permeabilization," Apoptosis, vol. 15, no. 5, pp. 527-540, 2010.

[177] T. Vanden Berghe, N. Vanlangenakker, E. Parthoens et al., "Necroptosis, necrosis and secondary necrosis converge on similar cellular disintegration features," Cell Death \& Differentiation, vol. 17, no. 6, pp. 922-930, 2010.

[178] P. Boya and G. Kroemer, "Lysosomal membrane permeabilization in cell death," Oncogene, vol. 27, no. 50, pp. 6434-6451, 2008.

[179] S. S. Mihardja, D. Gao, R. E. Sievers et al., "Targeted in vivo extracellular matrix formation promotes neovascularization in a rodent model of myocardial infarction," PLoS One, vol. 5, no. 4, article e10384, 2010.

[180] J. Hasegawa, I. Maejima, R. Iwamoto, and T. Yoshimori, "Selective autophagy: lysophagy," Methods, vol. 75, pp. 128132, 2015.

[181] I. Maejima, A. Takahashi, H. Omori et al., "Autophagy sequesters damaged lysosomes to control lysosomal 
biogenesis and kidney injury," The EMBO Journal, vol. 32, no. 17, pp. 2336-2347, 2013.

[182] M. Sardiello, M. Palmieri, A. di Ronza et al., "A gene network regulating lysosomal biogenesis and function," Science, vol. 325, no. 5939, pp. 473-477, 2009.

[183] M. Palmieri, S. Impey, H. Kang et al., "Characterization of the CLEAR network reveals an integrated control of cellular clearance pathways," Human Molecular Genetics, vol. 20, no. 19, pp. 3852-3866, 2011.

[184] C. Settembre, C. Di Malta, V. A. Polito et al., "TFEB links autophagy to lysosomal biogenesis," Science, vol. 332, no. 6036, pp. 1429-1433, 2011.

[185] N. Raben and R. Puertollano, "TFEB and TFE3: linking lysosomes to cellular adaptation to stress," Annual Review of Cell and Developmental Biology, vol. 32, no. 1, pp. 255-278, 2016.

[186] J. A. Martina, H. I. Diab, O. A. Brady, and R. Puertollano, "TFEB and TFE3 are novel components of the integrated stress response," The EMBO Journal, vol. 35, no. 5, pp. 479495, 2016.

[187] C. Settembre, A. Fraldi, D. C. Rubinsztein, and A. Ballabio, "Lysosomal storage diseases as disorders of autophagy," Autophagy, vol. 4, no. 1, pp. 113-114, 2008.

[188] F. P. Zummo, K. S. Cullen, M. Honkanen-Scott, J. A. M. Shaw, P. E. Lovat, and C. Arden, "Glucagon-like peptide 1 protects pancreatic $\beta$-cells from death by increasing autophagic flux and restoring lysosomal function," Diabetes, vol. 66, no. 5, pp. 1272-1285, 2017.

[189] I. Gukovsky, S. J. Pandol, and A. S. Gukovskaya, "Organellar dysfunction in the pathogenesis of pancreatitis," Antioxidants \& Redox Signaling, vol. 15, no. 10, pp. 2699-2710, 2011.

[190] A. Höhn and T. Grune, "Lipofuscin: formation, effects and role of macroautophagy," Redox Biology, vol. 1, no. 1, pp. 140-144, 2013.

[191] A. Terman and U. T. Brunk, "On the degradability and exocytosis of ceroid/lipofuscin in cultured rat cardiac myocytes," Mechanisms of Ageing and Development, vol. 100, no. 2, pp. 145-156, 1998.

[192] A. Terman and U. T. Brunk, "Lipofuscin," The International Journal of Biochemistry \& Cell Biology, vol. 36, no. 8, pp. 1400-1404, 2004.

[193] U. Brunk and A. Brun, "The effect of aging on lysosomal permeability in nerve cells of the central nervous system. An enzyme histochemical study in rat," Histochemie, vol. 30, no. 4, pp. 315-324, 1972.

[194] A. Höhn, T. Jung, S. Grimm, and T. Grune, "Lipofuscinbound iron is a major intracellular source of oxidants: role in senescent cells," Free Radical Biology \& Medicine, vol. 48, no. 8, pp. 1100-1108, 2010.

[195] M. Cnop, S. J. Hughes, M. Igoillo-Esteve et al., “The long lifespan and low turnover of human islet beta cells estimated by mathematical modelling of lipofuscin accumulation," Diabetologia, vol. 53, no. 2, pp. 321-330, 2010.

[196] M. Masini, M. Bugliani, R. Lupi et al., "Autophagy in human type 2 diabetes pancreatic beta cells," Diabetologia, vol. 52, no. 6, pp. 1083-1086, 2009.

[197] S. U. R. Mir, N. M. George, L. Zahoor, R. Harms, Z. Guinn, and N. E. Sarvetnick, "Inhibition of autophagic turnover in $\beta$-cells by fatty acids and glucose leads to apoptotic cell death," The Journal of Biological Chemistry, vol. 290, no. 10, pp. 6071-6085, 2015.
[198] N. Abuarab, T. S. Munsey, L.-H. Jiang, J. Li, and A. Sivaprasadarao, "High glucose-induced ROS activates TRPM2 to trigger lysosomal membrane permeabilization and $\mathrm{Zn}$ 2+-mediated mitochondrial fission," Science Signaling, vol. 10, no. 490, article eaal4161, 2017.

[199] J. Ji, M. Petropavlovskaia, A. Khatchadourian et al., "Type 2 diabetes is associated with suppression of autophagy and lipid accumulation in $\beta$-cells," Journal of Cellular and Molecular Medicine, vol. 23, no. 4, pp. 2890-2900, 2019.

[200] S. Bhansali, A. Bhansali, R. Walia, U. N. Saikia, and V. Dhawan, "Alterations in mitochondrial oxidative stress and mitophagy in subjects with prediabetes and type 2 diabetes mellitus," Frontiers in Endocrinology, vol. 8, 2017.

[201] H. Liu, A. Javaheri, R. J. Godar et al., "Intermittent fasting preserves beta-cell mass in obesity-induced diabetes via the autophagy-lysosome pathway," Autophagy, vol. 13, no. 11, pp. 1952-1968, 2017.

[202] P. C. Trivedi, J. J. Bartlett, L. J. Perez et al., “Glucolipotoxicity diminishes cardiomyocyte TFEB and inhibits lysosomal autophagy during obesity and diabetes," Biochimica et Biophysica Acta (BBA) - Molecular and Cell Biology of Lipids, vol. 1861, no. 12, pp. 1893-1910, 2016.

[203] M. Jung, J. Lee, H.-Y. Seo, J. S. Lim, and E.-K. Kim, “Cathepsin inhibition-induced lysosomal dysfunction enhances pancreatic beta-cell apoptosis in high glucose," PloS One, vol. 10, no. 1, article e0116972, 2015.

[204] G. Las, S. B. Serada, J. D. Wikstrom, G. Twig, and O. S. Shirihai, "Fatty acids suppress autophagic turnover in $\beta$ cells," The Journal of Biological Chemistry, vol. 286, no. 49, pp. 42534-42544, 2011.

[205] A. Salehi, R. Henningsson, H. Mosén, C.-G. Östenson, S. Efendic, and I. Lundquist, "Dysfunction of the islet lysosomal system conveys impairment of glucose-induced insulin release in the diabetic GK rat," Endocrinology, vol. 140, no. 7, pp. 3045-3053, 1999.

[206] J.-A. Lim, L. Li, O. S. Shirihai, K. M. Trudeau, R. Puertollano, and N. Raben, "Modulation of mTOR signaling as a strategy for the treatment of Pompe disease," EMBO Molecular Medicine, vol. 9, no. 3, pp. 353-370, 2017.

[207] J. Jia, Y. P. Abudu, A. Claude-Taupin et al., "Galectins control mTOR in response to endomembrane damage," Molecular Cell, vol. 70, no. 1, pp. 120-135.e8, 2018.

[208] U. Bandyopadhyay, M. Nagy, W. A. Fenton, and A. L. Horwich, "Absence of lipofuscin in motor neurons of SOD1-linked ALS mice," Proceedings of the National Academy of Sciences of the United States of America, vol. 111, no. 30, pp. 11055-11060, 2014.

[209] L. Lei, R. Tzekov, H. Li et al., "Inhibition or stimulation of autophagy affects early formation of lipofuscin-like autofluorescence in the retinal pigment epithelium cell," International Journal of Molecular Sciences, vol. 18, no. 4, p. 728, 2017.

[210] A. Öst, K. Svensson, I. Ruishalme et al., "Attenuated mTOR signaling and enhanced autophagy in adipocytes from obese patients with type 2 diabetes," Molecular Medicine, vol. 16, no. 7-8, pp. 235-246, 2010.

[211] L. El-Houjeiri, E. Possik, T. Vijayaraghavan et al., "The transcription factors TFEB and TFE3 link the FLCN-AMPK signaling axis to innate immune response and pathogen resistance," Cell Reports, vol. 26, pp. 3613-3628.e6, 2019.

[212] N. P. Young, A. Kamireddy, J. L. Van Nostrand et al., “AMPK governs lineage specification through Tfeb-dependent 
regulation of lysosomes," Genes \& Development, vol. 30, no. 5, pp. 535-552, 2016.

[213] L. Fernandez-Mosquera, K. F. Yambire, R. Couto et al., "Mitochondrial respiratory chain deficiency inhibits lysosomal hydrolysis," Autophagy, vol. 15, pp. 1572-1591, 2019.

[214] T. R. Whisenhunt, X. Yang, D. B. Bowe, A. J. Paterson, B. A. Van Tine, and J. E. Kudlow, "Disrupting the enzyme complex regulating O-GlcNAcylation blocks signaling and development," Glycobiology, vol. 16, no. 6, pp. 551-563, 2006.

[215] X. Yang, F. Zhang, and J. E. Kudlow, "Recruitment of OGlcNAc transferase to promoters by corepressor mSin3A: coupling protein O-GlcNAcylation to transcriptional repression," Cell, vol. 110, no. 1, pp. 69-80, 2002.

[216] J. Biwi, C. Biot, Y. Guerardel, A.-S. Vercoutter-Edouart, and T. Lefebvre, "The many ways by which O-GlcNAcylation may orchestrate the diversity of complex glycosylations," Molecules, vol. 23, no. 11, p. 2858, 2018.

[217] Y.-h. Lee, J. Kim, K. Park, and M.-S. Lee, “ $\beta$-cell autophagy: mechanism and role in $\beta$-cell dysfunction," Molecular Metabolism, vol. 27, pp. S92-S103, 2019.

[218] Y. Uchizono, C. Alarcón, B. L. Wicksteed, B. J. Marsh, and C. J. Rhodes, "The balance between proinsulin biosynthesis and insulin secretion: where can imbalance lead?," Diabetes, Obesity and Metabolism, vol. 9, no. s2, pp. 56-66, 2007.

[219] H. S. Jung, K. W. Chung, J. W. Kim et al., "Loss of autophagy diminishes pancreatic beta cell mass and function with resultant hyperglycemia," Cell Metabolism, vol. 8, no. 4, pp. 318$324,2008$.

[220] C. Ebato, T. Uchida, M. Arakawa et al., "Autophagy is important in islet homeostasis and compensatory increase of beta cell mass in response to high-fat diet," Cell Metabolism, vol. 8, no. 4, pp. 325-332, 2008.

[221] W. Quan, K. Y. Hur, Y. Lim et al., “Autophagy deficiency in beta cells leads to compromised unfolded protein response and progression from obesity to diabetes in mice," Diabetologia, vol. 55, no. 2, pp. 392-403, 2012.

[222] L. Orci, M. Ravazzola, M. Amherdt et al., "Insulin, not Cpeptide (proinsulin), is present in crinophagic bodies of the pancreatic B-cell," Journal of Cell Biology, vol. 98, no. 1, pp. 222-228, 1984.

[223] A. H. Schnell, I. Swenne, and L. A. Borg, "Lysosomes and pancreatic islet function," Cell and Tissue Research, vol. 252, no. 1, pp. 9-15, 1988.

[224] A. Weckman, A. Di Ieva, F. Rotondo et al., "Autophagy in the endocrine glands," Journal of Molecular Endocrinology, vol. 52, no. 2, pp. R151-R163, 2014.

[225] A. Goginashvili, Z. Zhang, E. Erbs et al., "Insulin granules. Insulin secretory granules control autophagy in pancreatic beta cells," Science, vol. 347, pp. 878-882, 2015.

[226] M. R. Marasco and A. K. Linnemann, " $\beta$-cell autophagy in diabetes pathogenesis," Endocrinology, vol. 159, no. 5, pp. 2127-2141, 2018.

[227] D. Glick, S. Barth, and K. F. Macleod, "Autophagy: cellular and molecular mechanisms," The Journal of Pathology, vol. 221, no. 1, pp. 3-12, 2010.

[228] B. Levine and G. Kroemer, "Autophagy in the pathogenesis of disease," Cell, vol. 132, no. 1, pp. 27-42, 2008.

[229] D. J. Klionsky, K. Abdelmohsen, A. Abe et al., "Guidelines for the use and interpretation of assays for monitoring autophagy," Autophagy, vol. 8, pp. 445-544, 2012.
[230] S. Bialik, S. K. Dasari, and A. Kimchi, "Autophagy-dependent cell death - where, how and why a cell eats itself to death," Journal of cell science, vol. 131, 2018.

[231] H. Mizukami, K. Takahashi, W. Inaba et al., "Involvement of oxidative stress-induced DNA damage, endoplasmic reticulum stress, and autophagy deficits in the decline of $\beta$-cell mass in Japanese type 2 diabetic patients," Diabetes care, vol. 37, 2014.

[232] H. Abe, T. Uchida, A. Hara et al., "Exendin-4 improves betacell function in autophagy-deficient beta-cells," Endocrinology, vol. 154, pp. 4512-4524, 2013.

[233] Y. Y. Chen, L. Q. Sun, B. A. Wang, X. M. Zou, Y. M. Mu, and J. M. Lu, "Palmitate induces autophagy in pancreatic $\beta$-cells via endoplasmic reticulum stress and its downstream JNK pathway," International journal of molecular medicine, vol. 32, 2013.

[234] L. Martino, M. Masini, M. Novelli et al., "Palmitate activates autophagy in INS-1E $\beta$-cells and in isolated rat and human pancreatic islets," PloS one, vol. 7, 2012.

[235] S. E. Choi, S. M. Lee, Y. J. Lee et al., "Protective role of autophagy in palmitate-induced INS-1 beta-cell death," Endocrinology, vol. 150, 2009.

[236] K. Fujimoto, P. T. Hanson, H. Tran et al., "Autophagy regulates pancreatic beta cell death in response to Pdx1 deficiency and nutrient deprivation," The Journal of biological chemistry, vol. 284, 2009.

[237] S. Yamamoto, K. Kuramoto, N. Wang et al., "Autophagy differentially regulates insulin production and insulin sensitivity," Cell reports, vol. 23, 2018.

[238] P. Serradas, M. H. Giroix, C. A. Saulnier et al., "Mitochondrial deoxyribonucleic acid content is specifically decreased in adult, but not fetal, pancreatic islets of the Goto-Kakizaki rat, a genetic model of noninsulin-dependent diabetes," Endocrinology, vol. 136, 1995.

[239] L. Chen, C. Liu, J. Gao et al., "Inhibition of Miro1 disturbs mitophagy and pancreatic $\beta$-cell function interfering insulin release via IRS-Akt-Foxo1 in diabetes," Oncotarget, vol. 8, 2017.

[240] X. Li, L. W. Chan, X. Li et al., "Obesity-induced regulator of calcineurin 1 overexpression leads to $\beta$-cell failure through mitophagy pathway inhibition," Antioxidants \& redox signaling, vol. 32, 2020.

[241] A. Hoshino, M. Ariyoshi, Y. Okawa et al., "Inhibition of p53 preserves Parkin-mediated mitophagy and pancreatic $\beta$-cell function in diabetes," Proceedings of the National Academy of Sciences of the United States of America, vol. 111, 2014.

[242] A. Bartolome, C. Guillen, and M. Benito, "Autophagy plays a protective role in endoplasmic reticulum stress-mediated pancreatic $\beta$ cell death," Autophagy, vol. 8, 2012.

[243] F. J. Kong, J. H. Wu, S. Y. Sun, and J. Q. Zhou, “The endoplasmic reticulum stress/autophagy pathway is involved in cholesterol-induced pancreatic $\beta$-cell injury," Scientific reports, vol. 7, 2017.

[244] M. Lambelet, L. F. Terra, M. Fukaya et al., "Dysfunctional autophagy following exposure to pro-inflammatory cytokines contributes to pancreatic $\beta$-cell apoptosis," Cell death \& disease, vol. 9, 2018.

[245] A. Tagawa, M. Yasuda, S. Kume et al., "Impaired podocyte autophagy exacerbates proteinuria in diabetic nephropathy," Diabetes, vol. 65, 2016. 
[246] C. H. Jung, S. H. Ro, J. Cao, N. M. Otto, and D. H. Kim, "mTOR regulation of autophagy," FEBS letters, vol. 584, 2010.

[247] Y. Jiang, W. Huang, J. Wang et al., "Metformin plays a dual role in MIN6 pancreatic beta cell function through AMPKdependent autophagy," International journal of biological sciences, vol. 10, pp. 268-277, 2014.

[248] D. Wang, M. Tian, Y. Qi et al., "Jinlida granule inhibits palmitic acid induced-intracellular lipid accumulation and enhances autophagy in NIT-1 pancreatic beta cells through AMPK activation," Journal of ethnopharmacology, vol. 161, pp. 99-107, 2015.

[249] J. Wu, J. J. Wu, L. J. Yang, L. X. Wei, and D. J. Zou, “Rosiglitazone protects against palmitate-induced pancreatic beta-cell death by activation of autophagy via 5'-AMP-activated protein kinase modulation," Endocrine, vol. 44, pp. 87-98, 2013.

[250] X. Yang and K. Qian, "Protein O-GlcNAcylation: emerging mechanisms and functions," Nature reviews. Molecular cell biology, vol. 18, 2017.

[251] S. A. Marsh, P. C. Powell, L. J. Dell'Italia, and J. C. Chatham, "Cardiac O-GlcNAcylation blunts autophagic signaling in the diabetic heart," Life sciences, vol. 92, 2013.

[252] X. Zhang, L. Wang, B. Lak, J. Li, E. Jokitalo, and Y. Wang, "GRASP55 senses glucose deprivation through OGlcNAcylation to promote autophagosome-lysosome fusion," Developmental cell, vol. 45, no. 2, pp. 245-261.e6, 2018.

[253] B. Guo, Q. Liang, L. Li et al., "O-GlcNAc-modification of SNAP-29 regulates autophagosome maturation," Nature cell biology, vol. 16, pp. 1215-1226, 2014.

[254] K. E. Pyo, C. R. Kim, M. Lee, J. S. Kim, K. I. Kim, and S. H. Baek, "ULK1 O-GlcNAcylation is crucial for activating VPS34 via ATG14L during autophagy initiation," Cell Reports, vol. 25, pp. 2878-2890 e2874, 2018.

[255] H. B. Ruan, Y. Ma, S. Torres et al., "Calcium-dependent OGlcNAc signaling drives liver autophagy in adaptation to starvation," Genes \& development, vol. 31, pp. 1655-1665, 2017.

[256] M. Rahman, H. Hwang, Y. Cho, and H. Rhim, "Modulation of O-GlcNAcylation regulates autophagy in cortical astrocytes," Oxidative Medicine and Cellular Longevity, vol. 2019, 13 pages, 2019.

[257] L. Wang, S. Chen, Z. Zhang et al., "Suppressed OGT expression inhibits cell proliferation while inducing cell apoptosis in bladder cancer," BMC cancer, vol. 18, 2018.

[258] F. Zhou, X. Yang, H. Zhao et al., "Down-regulation of OGT promotes cisplatin resistance by inducing autophagy in ovarian cancer," Theranostics, vol. 8, 2018.

[259] J. A. Ehses, A. Perren, E. Eppler et al., "Increased number of islet-associated macrophages in type 2 diabetes," Diabetes, vol. 56, pp. 2356-2370, 2007.

[260] M. Y. Donath, M. Boni-Schnetzler, H. Ellingsgaard, and J. A. Ehses, "Islet inflammation impairs the pancreatic beta-cell in type 2 diabetes," Physiology (Bethesda), vol. 24, pp. 325-331, 2009.

[261] T. Ogihara and R. G. Mirmira, "An islet in distress: $\beta$ cell failure in type 2 diabetes," Journal of Diabetes Investigation, vol. 1, pp. 123-133, 2010.

[262] H. Yi, R. Peng, L. Y. Zhang et al., "LincRNA-Gm4419 knockdown ameliorates NF- $\kappa \mathrm{B} / \mathrm{NLRP} 3$ inflammasome-mediated inflammation in diabetic nephropathy," Cell death \& disease, vol. $8,2017$.
[263] P. Dandona, A. Aljada, A. Chaudhuri, P. Mohanty, and R. Garg, "Metabolic syndrome: a comprehensive perspective based on interactions between obesity, diabetes, and inflammation," Circulation, vol. 111, 2005.

[264] G. W. Novotny, M. Lundh, M. B. Backe et al., "Transcriptional and translational regulation of cytokine signaling in inflammatory $\beta$-cell dysfunction and apoptosis," Archives of biochemistry and biophysics, vol. 528, pp. 171-184, 2012.

[265] S. Cernea and M. Dobreanu, "Diabetes and beta cell function: from mechanisms to evaluation and clinical implications," Biochemia medica: Biochemia medica, vol. 23, pp. 266-280, 2013.

[266] M. Böni-Schnetzler, J. Thorne, G. Parnaud et al., "Increased interleukin (IL)-1beta messenger ribonucleic acid expression in beta -cells of individuals with type 2 diabetes and regulation of IL-1beta in human islets by glucose and autostimulation," The Journal of Clinical Endocrinology \& Metabolism, vol. 93, pp. 4065-4074, 2008.

[267] K. Eguchi and R. Nagai, "Islet inflammation in type 2 diabetes and physiology," The Journal of Clinical Investigation, vol. 127, pp. 14-23, 2017.

[268] H. Khodabandehloo, S. Gorgani-Firuzjaee, G. Panahi, and R. Meshkani, "Molecular and cellular mechanisms linking inflammation to insulin resistance and $\beta$-cell dysfunction," Translational Research, vol. 167, pp. 228-256, 2016.

[269] U. Ozcan, L. Ozcan, E. Yilmaz et al., "Loss of the tuberous sclerosis complex tumor suppressors triggers the unfolded protein response to regulate insulin signaling and apoptosis," Molecular cell, vol. 29, pp. 541-551, 2008.

[270] O. N. Ozes, H. Akca, L. D. Mayo et al., "A phosphatidylinositol 3-kinase/Akt/mTOR pathway mediates and PTEN antagonizes tumor necrosis factor inhibition of insulin signaling through insulin receptor substrate-1," Proceedings of the National Academy of Sciences, vol. 98, pp. 4640-4645, 2001.

[271] D. F. Lee, H. P. Kuo, C. T. Chen et al., "IKKbeta suppression of TSC1 function links the mTOR pathway with insulin resistance," International journal of molecular medicine, vol. 22, pp. 633-638, 2008.

[272] T. Weichhart, M. Hengstschlager, and M. Linke, "Regulation of innate immune cell function by mTOR," Nature Reviews. Immunology, vol. 15, pp. 599-614, 2015.

[273] P. Yang, Y. Zhao, L. Zhao et al., "Paradoxical effect of rapamycin on inflammatory stress-induced insulin resistance in vitro and in vivo," Scientific reports, vol. 5, article 14959, 2015.

[274] J. A. Groves, A. Lee, G. Yildirir, and N. E. Zachara, "Dynamic O-GlcNAcylation and its roles in the cellular stress response and homeostasis," Cell Stress \& Chaperones, vol. 18, pp. 535-558, 2013.

[275] Y. Li, M. Xie, L. Men, and J. Du, "O-GlcNAcylation in immunity and inflammation: an intricate system (review)," International Journal of Molecular Medicine, vol. 44, pp. 363-374, 2019.

[276] L. Baudoin and T. Issad, "O-GlcNAcylation and inflammation: a vast territory to explore," Frontiers in endocrinology, vol. 5, p. 235, 2014

[277] P. Ramakrishnan, P. M. Clark, D. E. Mason, E. C. Peters, L. C. Hsieh-Wilson, and D. Baltimore, "Activation of the transcriptional function of the NF- $\kappa \mathrm{B}$ protein $c$-Rel by $\mathrm{O}$ - 
GlcNAc glycosylation," Science signaling, vol. 6, article ra75, 2013.

[278] R. G. Baker, M. S. Hayden, and S. Ghosh, "NF- $\kappa$ B, inflammation, and metabolic disease," Cell Metabolism, vol. 13, pp. 1122, 2011.

[279] S. M. Grundy, "Overnutrition, ectopic lipid and the metabolic syndrome," Journal of Investigative Medicine, vol. 64, pp. 1082-1086, 2016.

[280] H. Y. Chung, M. Cesari, S. Anton et al., "Molecular inflammation: underpinnings of aging and age-related diseases," Ageing research reviews, vol. 8, pp. 18-30, 2009.

[281] M. Y. Donath and S. E. Shoelson, "Type 2 diabetes as an inflammatory disease," Nature Reviews. Immunology, vol. 11, pp. 98-107, 2011.

[282] M. Bagnati, B. W. Ogunkolade, C. Marshall et al., "Glucolipotoxicity initiates pancreatic beta-cell death through TNFR5/CD40-mediated STAT1 and NF-kappaB activation," Cell death \& disease, vol. 7, article e2329, 2016.

[283] H. C. Dan, M. J. Cooper, P. C. Cogswell, J. A. Duncan, J. P. Ting, and A. S. Baldwin, "Akt-dependent regulation of NF\{kappa\}B is controlled by mTOR and Raptor in association with IKK," Genes \& development, vol. 22, pp. 1490-1500, 2008.

[284] J. Dai, C. Jiang, H. Chen, and Y. Chai, "Rapamycin attenuates high glucose-induced inflammation through modulation of mTOR/NF-kappaB pathways in macrophages," Frontiers in Pharmacology, vol. 10, p. 1292, 2019.

[285] W. H. Yang, S. Y. Park, H. W. Nam et al., "NFkappaB activation is associated with its O-GlcNAcylation state under hyperglycemic conditions," Proceedings of the National Academy of Sciences, vol. 105, pp. 17345-17350, 2008.

[286] D. F. Allison, J. J. Wamsley, M. Kumar et al., "Modification of RelA by O-linked $\mathrm{N}$-acetylglucosamine links glucose metabolism to NF- $\kappa \mathrm{B}$ acetylation and transcription," Proceedings of the National Academy of Sciences, vol. 109, pp. 1688816893, 2012.

[287] D. Zhang, Y. Cai, M. Chen, L. Gao, Y. Shen, and Z. Huang, "OGT-mediated O-GlcNAcylation promotes NF-kappaB activation and inflammation in acute pancreatitis," Inflammation Research, vol. 64, pp. 943-952, 2015.

[288] Q. Zhang, M. J. Lenardo, and D. Baltimore, "30 years of NF$\kappa \mathrm{B}$ : a blossoming of relevance to human pathobiology," Cell, vol. 168, pp. 37-57, 2017.

[289] J. M. Olefsky and C. K. Glass, "Macrophages, inflammation, and insulin resistance," Annual Review of Physiology, vol. 72, pp. 219-246, 2010.

[290] K. Eguchi and I. Manabe, "Macrophages and islet inflammation in type 2 diabetes," Diabetes, Obesity \& Metabolism, vol. 15, Suppl 3, pp. 152-158, 2013.

[291] C. N. Lumeng, J. L. Bodzin, and A. R. Saltiel, "Obesity induces a phenotypic switch in adipose tissue macrophage polarization," The Journal of Clinical Investigation, vol. 117, pp. 175-184, 2007.

[292] C. Y. Westwell-Roper, J. A. Ehses, and C. B. Verchere, "Resident macrophages mediate islet amyloid polypeptideinduced islet IL- $1 \beta$ production and $\beta$-cell dysfunction," Diabetes, vol. 63, pp. 1698-1711, 2014.

[293] K. Eguchi, I. Manabe, Y. Oishi-Tanaka et al., "Saturated fatty acid and TLR signaling link $\beta$ cell dysfunction and islet inflammation," Cell metabolism, vol. 15, pp. 518533, 2012.
[294] N. Shanmugam, M. A. Reddy, M. Guha, and R. Natarajan, "High glucose-induced expression of proinflammatory cytokine and chemokine genes in monocytic cells," Diabetes, vol. 52, pp. 1256-1264, 2003.

[295] X. Xiao, I. Gaffar, P. Guo et al., "M2 macrophages promote beta-cell proliferation by up-regulation of SMAD7," Proceedings of the National Academy of Sciences, vol. 111, pp. E1211E1220, 2014.

[296] M. Y. Donath, "Targeting inflammation in the treatment of type 2 diabetes: time to start," Nature Reviews. Drug Discovery, vol. 13, pp. 465-476, 2014.

[297] K. Maedler, P. Sergeev, F. Ris et al., "Glucose-induced $\beta$ cell production of IL- $1 \beta$ contributes to glucotoxicity in human pancreatic islets," The Journal of clinical investigation, vol. 127, article 1589, 2017.

[298] P. Menu, A. Mayor, R. Zhou et al., "ER stress activates the NLRP3 inflammasome via an UPR-independent pathway," Cell death \& disease, vol. 3, article e261, 2012.

[299] R. Zhou, A. Tardivel, B. Thorens, I. Choi, and J. Tschopp, "Thioredoxin-interacting protein links oxidative stress to inflammasome activation," Nature Immunology, vol. 11, pp. 136-140, 2010.

[300] H. M. Lee, J. J. Kim, H. J. Kim, M. Shong, B. J. Ku, and E. K. Jo, "Upregulated NLRP3 inflammasome activation in patients with type 2 diabetes," Diabetes, vol. 62, pp. 194204, 2013.

[301] M. Boni-Schnetzler, S. Boller, S. Debray et al., "Free fatty acids induce a proinflammatory response in islets via the abundantly expressed interleukin-1 receptor I," Endocrinology, vol. 150, pp. 5218-5229, 2009.

[302] J. A. Ehses, G. Lacraz, M. H. Giroix et al., "IL-1 antagonism reduces hyperglycemia and tissue inflammation in the type 2 diabetic GK rat," Proceedings of the National Academy of Sciences, vol. 106, pp. 13998-14003, 2009.

[303] K. Maedler, G. A. Spinas, R. Lehmann et al., "Glucose induces beta-cell apoptosis via upregulation of the Fas receptor in human islets," Diabetes, vol. 50, pp. 1683-1690, 2001.

[304] M. Y. Donath, M. Böni-Schnetzler, H. Ellingsgaard, P. A. Halban, and J. A. Ehses, "Cytokine production by islets in health and diabetes: cellular origin, regulation and function," Trends in Endocrinology and Metabolism, vol. 21, pp. 261267, 2010.

[305] A. K. Cardozo, F. Ortis, J. Storling et al., "Cytokines downregulate the sarcoendoplasmic reticulum pump Ca2+ ATPase $2 b$ and deplete endoplasmic reticulum $\mathrm{Ca} 2+$, leading to induction of endoplasmic reticulum stress in pancreatic beta-cells," Diabetes, vol. 54, pp. 452-461, 2005.

[306] N. Dali-Youcef, M. Mecili, R. Ricci, and E. Andrès, "Metabolic inflammation: connecting obesity and insulin resistance," Annals of Medicine, vol. 45, pp. 242-253, 2013.

[307] M. A. McGuckin, R. D. Eri, I. Das, R. Lourie, and T. H. Florin, "ER stress and the unfolded protein response in intestinal inflammation," American Journal of Physiology. Gastrointestinal and Liver Physiology, vol. 298, pp. G820-G832, 2010.

[308] C. M. Oslowski, T. Hara, B. O'Sullivan-Murphy et al., “Thioredoxin-interacting protein mediates ER stress-induced beta cell death through initiation of the inflammasome," Cell metabolism, vol. 16, pp. 265-273, 2012.

[309] M. I. Miani, J. Barthson, M. L. Colli, F. Brozzi, M. Cnop, and D. L. Eizirik, "Endoplasmic reticulum stress sensitizes pancreatic beta cells to interleukin- $\beta$-induced apoptosis via 
Bim/A1 imbalance," Cell death \& disease, vol. 4, article e701, 2013.

[310] F. A. Grieco, A. A. Schiavo, F. Brozzi et al., "The miRNAs miR-211-5p and miR-204-5p modulate ER stress in human beta cells," Journal of molecular endocrinology, vol. 63, pp. 139-149, 2019.

[311] I. Kharroubi, L. Ladrière, A. K. Cardozo, Z. Dogusan, M. Cnop, and D. L. Eizirik, "Free fatty acids and cytokines induce pancreatic beta-cell apoptosis by different mechanisms: role of nuclear factor-kappaB and endoplasmic reticulum stress," Endocrinology, vol. 145, pp. 5087-5096, 2004.

[312] D. Bending, P. Zaccone, and A. Cooke, "Inflammation and type one diabetes," International Immunology, vol. 24, pp. 339-346, 2012.

[313] J. Rowlands, J. Heng, P. Newsholme, and R. Carlessi, "Pleiotropic effects of GLP-1 and analogs on cell signaling, metabolism, and function," Frontiers in endocrinology, vol. 9, p. $672,2018$.

[314] S. Tsunekawa, N. Yamamoto, K. Tsukamoto et al., "Protection of pancreatic beta-cells by exendin- 4 may involve the reduction of endoplasmic reticulum stress; in vivo and in vitro studies," Journal of Endocrinology, vol. 193, pp. 6574, 2007.

[315] B. Yusta, L. L. Baggio, J. L. Estall et al., "GLP-1 receptor activation improves beta cell function and survival following induction of endoplasmic reticulum stress," Cell metabolism, vol. 4, pp. 391-406, 2006.

[316] D. A. Cunha, L. Ladrière, F. Ortis et al., "Glucagon-like peptide-1 agonists protect pancreatic beta-cells from lipotoxic endoplasmic reticulum stress through upregulation of BiP and JunB," Diabetes, vol. 58, pp. 2851-2862, 2009.

[317] M. Y. Kang, T. J. Oh, and Y. M. Cho, "Glucagon-like peptide1 increases mitochondrial biogenesis and function in INS-1 rat insulinoma cells," Endocrinology and Metabolism, vol. 30, pp. 216-220, 2015.

[318] R. Fan, X. Li, X. Gu, J. C. Chan, and G. Xu, "Exendin-4 protects pancreatic beta cells from human islet amyloid polypeptide-induced cell damage: potential involvement of AKT and mitochondria biogenesis," Diabetes, Obesity \& Metabolism, vol. 12, pp. 815-824, 2010.

[319] J. Wang, J. Wu, H. Wu et al., "Liraglutide protects pancreatic beta-cells against free fatty acids in vitro and affects glucolipid metabolism in apolipoprotein E-/- mice by activating autophagy," Molecular medicine reports, vol. 12, pp. 42104218, 2015.

[320] R. A. Saxton and D. M. Sabatini, "mTOR signaling in growth, metabolism, and disease," Cell, vol. 168, pp. 960-976, 2017.

[321] K. H. Schreiber, S. I. Apelo, D. Yu et al., "A novel rapamycin analog is highly selective for mTORC1 in vivo," Nature communications, vol. 10, article 3194, 2019.

[322] S. A. Kang, D. J. O'Neill, A. W. Machl et al., "Discovery of small-molecule selective mTORC1 inhibitors via direct inhibition of glucose transporters," Cell chemical biology, vol. 26, pp. 1203-1213 e1213, 2019.

[323] Y. Wang, J. Zhu, and L. Zhang, "Discovery of cell-permeable O-GlcNAc transferase inhibitors via tethering in situ click chemistry," Journal of Medicinal Chemistry, vol. 60, pp. 263-272, 2017.

[324] R. F. Ortiz-Meoz, J. Jiang, M. B. Lazarus et al., "A small molecule that inhibits OGT activity in cells," ACS chemical biology, vol. 10, pp. 1392-1397, 2015.
[325] H. Zhang, T. Tomašič, J. Shi et al., "Inhibition of O-GlcNAc transferase (OGT) by peptidic hybrids," MedChem Comm, vol. 9, pp. 883-887, 2018.

[326] S. I. Arriola Apelo, J. C. Neuman, E. L. Baar et al., "Alternative rapamycin treatment regimens mitigate the impact of rapamycin on glucose homeostasis and the immune system," Aging Cell, vol. 15, pp. 28-38, 2016.

[327] M. V. Blagosklonny, "Fasting and rapamycin: diabetes versus benevolent glucose intolerance," Cell Death \& Disease, vol. 10, p. 607, 2019. 